\title{
High-Frequency Translational Agitation with Micro Pin-Fin Surfaces for Enhancing Heat Transfer of Forced Convection
}

\author{
Taiho Yeom ${ }^{\text {a }}$, Terrence W. Simon ${ }^{\text {a }}$, Mark North ${ }^{\mathrm{b}}$, and Tianhong Cui ${ }^{\mathrm{a}, *}$ \\ ${ }^{a}$ Department of Mechanical Engineering, University of Minnesota, Minneapolis, MN 55455, USA \\ ${ }^{\mathrm{b}}$ Thermacore Inc., 780 Eden Road, Lancaster, PA 1760, USA
}

\footnotetext{
* Corresponding author. Tel: +1 612626 1636; fax: +1 6126256069

E-mail address: cuixx006@me.umn.edu
} 


\begin{abstract}
An advanced air cooling scheme that combines both active and passive cooling components is proposed and its thermal performance is demonstrated with single channel heat transfer experiments. The active cooling component, a piezoelectric translational agitator, generates strong air turbulence using a blade oscillating at a high frequency near either plain or micro pinfin surfaces in the channel. The translational agitation of the blade is realized using an oval loop shell amplifier with a piezoelectric stack actuator. The micro pin-fin surfaces were fabricated by the LIGA photolithography technique. Single channel heat transfer experiments show promising results in the combined system with the micro pin-fin surface and the agitator. For instance, the combined system heat transfer coefficients were $250 \%$ of those on smooth surfaces without agitation. The channel flow rate was 40 LPM and the Reynolds number was 3300. Measurements are presented that assess, pin fin and agitation effects on thermal performance of the proposed active heat sink system for several channel flow rates. Based on these single channel test results, a multi-channel, full-size, active heat sink system utilizing micro pin fins and translational agitators is proposed, and its thermal performance is estimated.
\end{abstract}

\title{
Keywords
}

Electronics cooling, translational agitation, piezoelectricity, micro pin fin, flow agitator, active heat sink 


\section{Introduction}

Effective cooling has been a critical issue for electronics from small portable devices such as smart phones to high power processing computers as failure of effective heat removal results in poor efficiency or damage to electronics systems. Large heat dissipation of several hundred Watts or even up to several kilowatts has led to implementation of complex liquid cooling schemes such as spray, boiling, etc. [1-6]. In spite of superior heat transfer performance of liquid cooling methods, air cooling is still an attractive thermal management scheme for its many advantages over liquid cooling, including simplicity, reliability, cost, etc. These factors have been driving forces for development of many passive or active air cooling technologies to postpone transition to liquid cooling. A piezoelectric fan is one of the newly introduced methods for active air cooling. A piezoelectric ceramic generates a flapping motion of a thin elastic blade, usually at its resonance frequency, yielding air motion and turbulence from its flapping tip. A variety of piezoelectric fans of different configurations have been reported in the literature since Toda and Osaka [7] introduced the piezo fan as a cooling device. Yoo et al. [8] investigated the vibrational characteristics of bimorph piezoelectric fans operating at about $60 \mathrm{~Hz}$. The lengths of the fans ranged from 28.6 to $69 \mathrm{~mm}$. Different shim materials were tried and their structural responses were analyzed theoretically. The maximum peak-to-peak displacement of $35.5 \mathrm{~mm}$ was achieved from a phosphor bronze fan driven at $60 \mathrm{~Hz}$ with 220 Volts. Açikalin et al. [9] conducted a design study of piezo fans noting their utility in small portable electronics with their low noise and power consumption. The piezoelectric fan was $63.5 \mathrm{~mm}$ long and generated a peak-to-peak amplitude of $15 \mathrm{~mm}$ with an operating frequency of $20 \mathrm{~Hz}$. They studied thermal performance of the fan with different mounting configurations relative to the heated surface achieving a largest heat transfer coefficient of $102 \mathrm{~W} / \mathrm{m}^{2} \mathrm{~K}$. They also demonstrated the thermal 
performance of a fan in a laptop environment. Flow visualization was provided to support their measurements. Higher resonance modes of piezoelectric fans were investigated with finite element and experimental methods by Wait et al. [10]. They concluded that the second modes of operation is desirable, considering the electromechanical coupling factor for conversion from electrical to mechanical energy. However, higher mode operation was accompanied by increased power consumption. Açikalin and Garimella [11] predicted fundamental characteristics of piezoelectric fans, such as flow fields around the fans and associated fan curves as well as heat transfer performance. Kimber et al. [12] demonstrated localized heat transfer enhancements with $60 \mathrm{~Hz}$ and $6.35-10 \mathrm{~mm}$ amplitude operation yielding heat transfer coefficients of about 100 $\mathrm{W} / \mathrm{m}^{2} \mathrm{~K}$. They found that an optimal tip-to-surface gap is closely related to the vibration amplitude of the fans. Liu et al. [13] examined influences of fan geometry and arrangement with six different piezoelectric fans. Operating frequencies ranged from 28 to $53 \mathrm{~Hz}$. The thermal enhancement ratios of their fans over natural convection were as high as three. Thus, the piezoelectric fan with an operating frequency of less than $100 \mathrm{~Hz}$ has various advantages, such as low noise level, low power consumption and compactness, for application to small-scale electronics. However, localized and confined heat transfer areas and low heat transfer coefficients make the flapping fans unsuitable for cooling of high power electronics.

Piezoelectric drives are used also in synthetic jets, devices that generate a net zero mass flow out of a cavity. Consisting of a drive, a diaphragm, a cavity and an orifice, they have gained much attention, recently, for localized cooling purposes. Beratlis and Smith [14] performed a numerical study to optimize a synthetic jet for cooling vertical cavity surfaces of a laser array. Their optimization parameters were the jet angle and distance from a heated surface. Mahalingam et al. [15] fabricated a synthetic jet ejector that generates secondary flows in a 
channel, then studied the effect of channel width on flow characteristics and thermal performance. An active heat sink combined with the synthetic jet ejector was tested to demonstrate $110 \mathrm{~W}$ dissipation of thermal energy while maintaining the heat sink temperature at $100{ }^{\circ} \mathrm{C}$. This was a $350 \%$ improvement over natural convection. Wang et al. [16] embedded a synthetic jet into a printed wiring board used for the thermal management of microelectronics. A flexible polymeric diaphragm was driven by an electromagnetic driver. The synthetic jet achieved a peak jet velocity of $14 \mathrm{~m} / \mathrm{s}$ with $60 \mathrm{~mW}$ of power and achieved heat flux removal of 3.6 W/ $\mathrm{cm}^{2}$ keeping the surface temperature below $70^{\circ} \mathrm{C}$. Pavlova and Amitay [17] found that synthetic jets are three times more effective than continuous jets operating at the same Reynolds number. They conducted a detailed flow visualization study to understand the cooling mechanism at different operating frequencies. Arik [18] investigated the localized heat transfer of a piezoelectric synthetic jet operating between $2 \mathrm{kHz}$ and $6 \mathrm{kHz}$. They also studied the effects of applied voltages, frequencies, and heater lengths on cooling. One case provided 10 times natural convection heat transfer.

Combining these devices with a passive cooling system that provides increased heat transfer area (fins) may further enhance cooling capability. The passive method in the present study includes micro pin fin structures that can disturb the thermal boundary layers in addition to providing the increased heat transfer area. Intensive investigation on thermal and hydrodynamic aspects of pin fin structures is documented in the literature. Studies about heat transfer and pressure drop characteristics of conventional size pin fins with different array orientations [19-21] or cross sectional shapes $[19,21-25]$ were reported. Overall, the studies suggested that a staggered array is superior to an in-lined array in terms of heat transfer capability. With technology advances in microfabrication, a remarkable size reduction of pin fin structures is 
possible. As a result, micro pin fins have recently gained considerable attention for thermal management. Marques and Kelly [26] demonstrated fabrication of micro pin fins onto planar or non-planar metal surfaces. Their results showed enhanced heat transfer performance over plain heat exchanger systems. Koşar et al. [27] documented pressure drop characteristics of laminar flow of water over micro pin-fin arrays of different orientations and shapes. Correlations for conventional pin fins were in need of modification for use with micro pin fins to account for the effects of pin fin height-to-diameter ratio, which tend to be smaller in micro pin fin arrays. Additionally, they showed that staggered and diamond-shaped pin fins generated higher friction factors than in-lined and circular-shaped fins. Peles et al. [28] documented heat transfer with a bank of micro pin fins and derived a correlation for total thermal resistance. Their results recommend that a dense micro pin fin configuration is preferable at high Reynolds number operation. Prasher et al. [29] provided extensive correlation data of Nusselt numbers and friction factors for micro pin fins with staggered arrays and water cross flows.

In the present study, we investigate an advanced air cooling technique that combines both active and passive methods for developing an active heat sink system. Herein, the active method is a piezoelectric translational agitator that generates strong air turbulence from oscillating blade plates with high-frequency translational displacements. The passive method is the use of micro pin fins grown on the heat sink channel surface. Yeom et al. [30] introduced the concept of the agitator with an oval loop shell piezo actuator, and demonstrated its possibility as a cooling device. In addition, Yeom et al. [31] investigated heat transfer performance of the agitator over plain heated surfaces in a channel with different operating conditions. The active heat sink system that combined micro pin-fin surfaces and translational agitators was introduced by Yeom et al. [32]. Yu et al. [33] experimentally and numerically studied the active heat sink system 
integrated with translational agitators and synthetic jets in a single channel. Current work extends these previous studies and provides intensive heat transfer experimental results for the piezoelectric translational agitator operating over micro pin-fin surfaces focusing on performance in a single channel. Thermal performance of a full-size active heat sink system aided by a multiple-blade agitator system and micro pin-fin surfaces is anticipated, based on the results from the present single-channel heat transfer experiments.

\section{Translational agitation over micro pin-fin surfaces}

\subsection{Piezoelectric translational agitator (PTA)}

The high frequency translational motion of rigid rectangular blade is made using resonance energy of an oval loop shell amplifier excited by a PZT stack actuator. The shell is compressing the PZT actuator in the center of the loop. The PZT actuator generates sinusoidal vibration with a micron-range displacement in its axial (x) direction (Fig. 1(a)). The oval loop shell has two flexural beam sections that vibrate at their resonance. A carbon fiber composite blade structure is attached to the center on one of the two flexural beams. The other side of the shell is fixed by using the "fixed bump" shown. When the PZT actuator generates vibration with frequencies close to the natural frequencies of the oval loop shell amplifier, the flexural beam, with the blade attached, is vigorously excited in the y-direction, as indicated in Fig. 1(a), making millimeter-range amplified displacements. Figure 1(b) shows the actuator at its idle state with a stationary beam and blade. The excited beam and oscillating blade at resonance of the actuator is seen by the fuzziness in Fig. 1(c). By changing the thickness of the beam and the size of the oval loop shell actuator, the operating frequency and displacement are modified. More detailed analyses on vibrational and structural characteristics of the oval loop shell actuator can be found in the previous work [30]. 
(a)

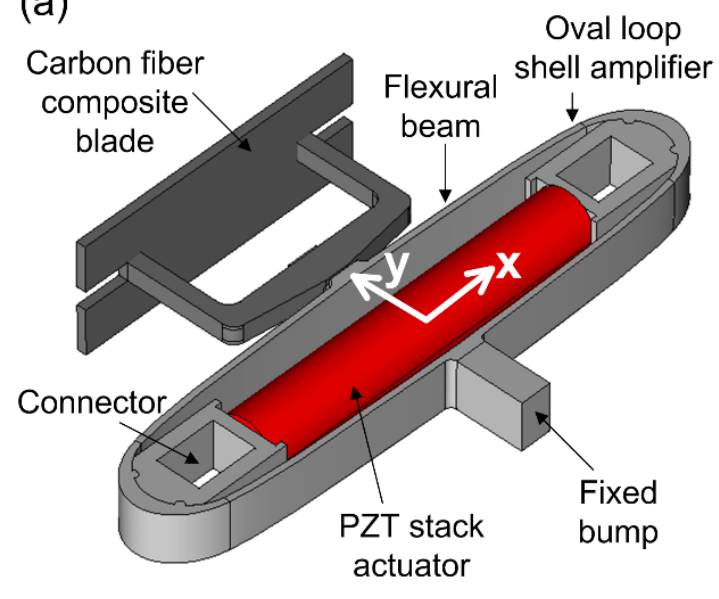

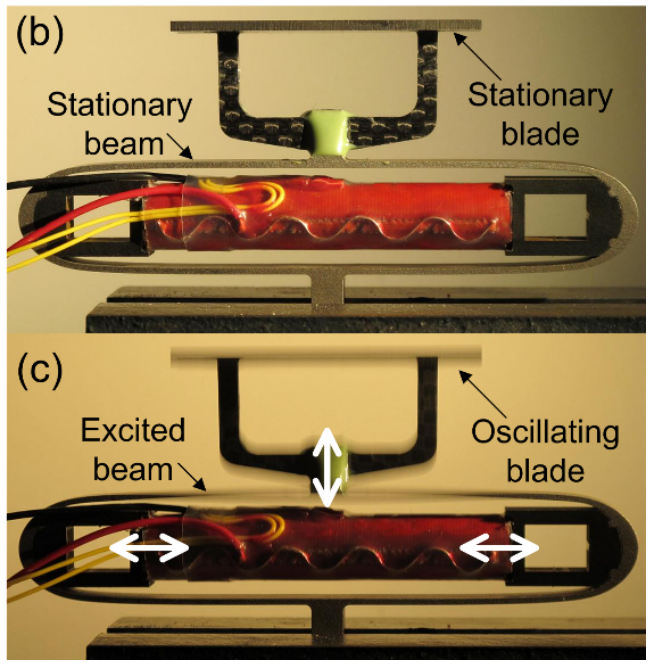

Fig. 1(a) Piezoelectric translational agitator (PTA), (b) PTA at the idle state, (c) operation mode of the PTA.

\subsection{PTA with micro pin-fin surfaces}

In order to demonstrate thermal performance of the actuator and micro pin-fin surface combination, a single channel test facility is considered. Figure 2 shows a conceptual illustration of the single channel housed with the actuator and the micro pin-fin surface. In the center of channel, the thin copper plate with micro pin fin arrays is positioned and the agitator blade faces the micro pin-fin surface and moves with high-frequency, translational oscillation (expressed as white arrows in Fig. 2). The micro pin-fin surface represents a side surface of the active heat sink channel. Air flow passes from left to right in the channel. 


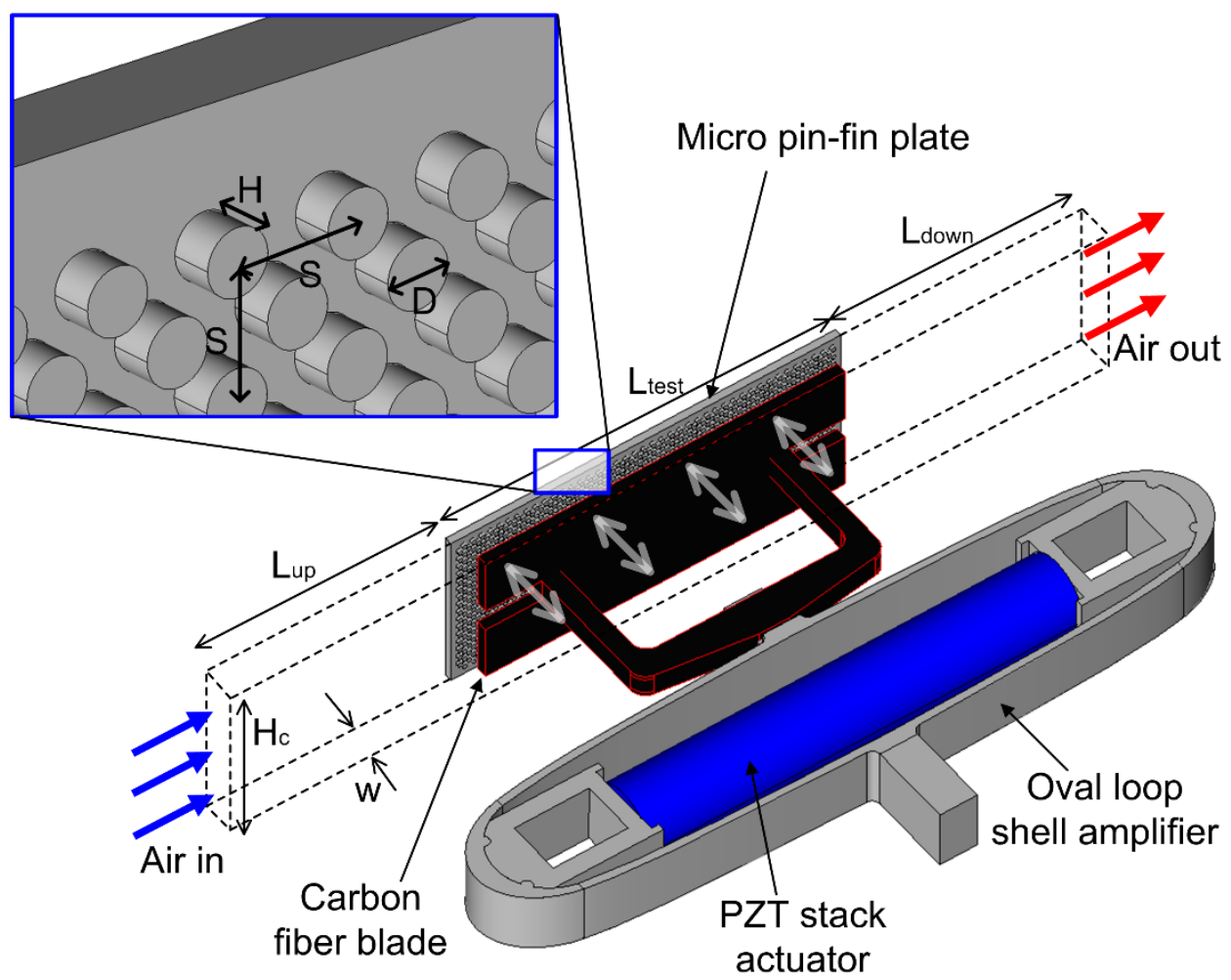

Fig. 2 Illustration of translational agitator operating with micro pin-fin plate in a narrow channel

The micro pin fin has diameter, $\mathrm{D}$, and height, $\mathrm{H}$. The pitch between the pin fins is $\mathrm{S}$, the same in both horizontal and vertical directions. Micro pin fins are fabricated on a thin copper plate by the LIGA photolithography technique, as explained in Fig. 3. First, the $\sim 10 \mathrm{~cm}$ (4-inch) copper wafer is prepared to make the fabrication process easier. Next, a cleaning process is performed with acetone, methanol, isopropyl alcohol, potassium hydroxide and sulfuric acid. A deposition of titanium (Ti) follows, to serve as a protective layer (Fig. 3(a)). A KMPR photoresist layer is deposited on the Ti layer (Fig. 3(b)). Then the photoresist and Ti layers are patterned and etched. Micro pin fins are electroplated onto the preprocessed copper wafer in a copper plating bath. Finally, the residuals of photoresist and Ti layers are removed and only the copper micro pin fin structures remain (Fig. 3(e)). A Scanning Electron Microscope (SEM) image of the fabricated micro pin-fin array is shown in Fig. 3(f). 


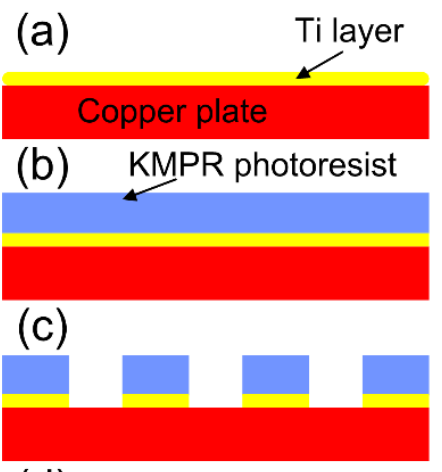

(d)

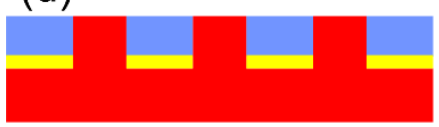

(e)

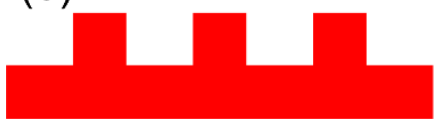

(f)

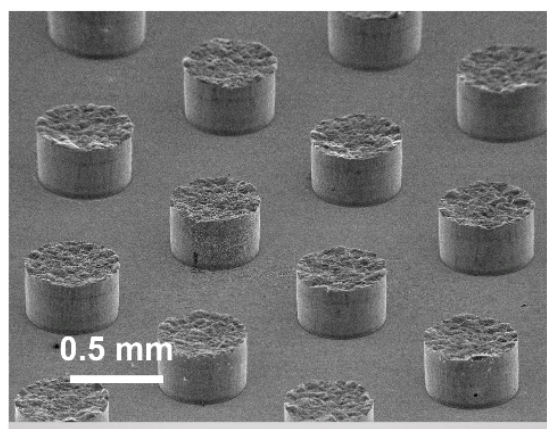

(g)

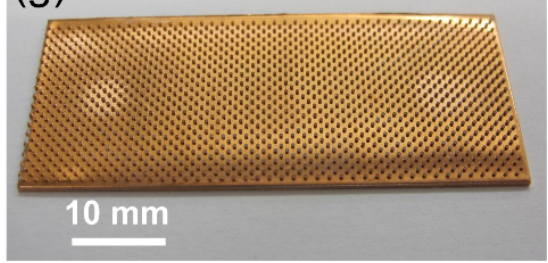

Fig. 3 Fabrication process of copper micro pin-fin plate, (a) Ti metal layer deposition, (b) KMPR photoresist deposition, (c) photoresist patterning and Ti layer etching, (d) electroplating of copper micro pin fins, (e) removal of KMPR photoresist and Ti layer residuals, (f) SEM image of micro pin-fin array and (g) micro pin-fin plate

The details of heat transfer experiment facility are illustrated in Fig. 4. A long rectangular copper block is used as a heat flow path from the heater to the micro pin-fin surface. At one end is a cartridge heater. At the other end is the micro pin-fin surface plate, attached using a thermal paste. The copper block is insulated with Styrofoam to minimize heat loss. The micro pin-fin surface is exposed to air flow in the channel, as shown in Fig. 2. The channel unheated surfaces are acrylic plastic plates with Styrofoam backing. The channel has adiabatic upstream and downstream extension sections ( $\mathrm{L}_{\text {up }}$ and $\mathrm{L}_{\text {down }}$ in Fig. 2). The agitator blade is positioned in the center of the channel length. Frames that connect the blade to the oval loop shell pass through holes in the plastic wall of the channel. The holes for the frames are sealed using flexible latex to ensure that there is no leakage. 


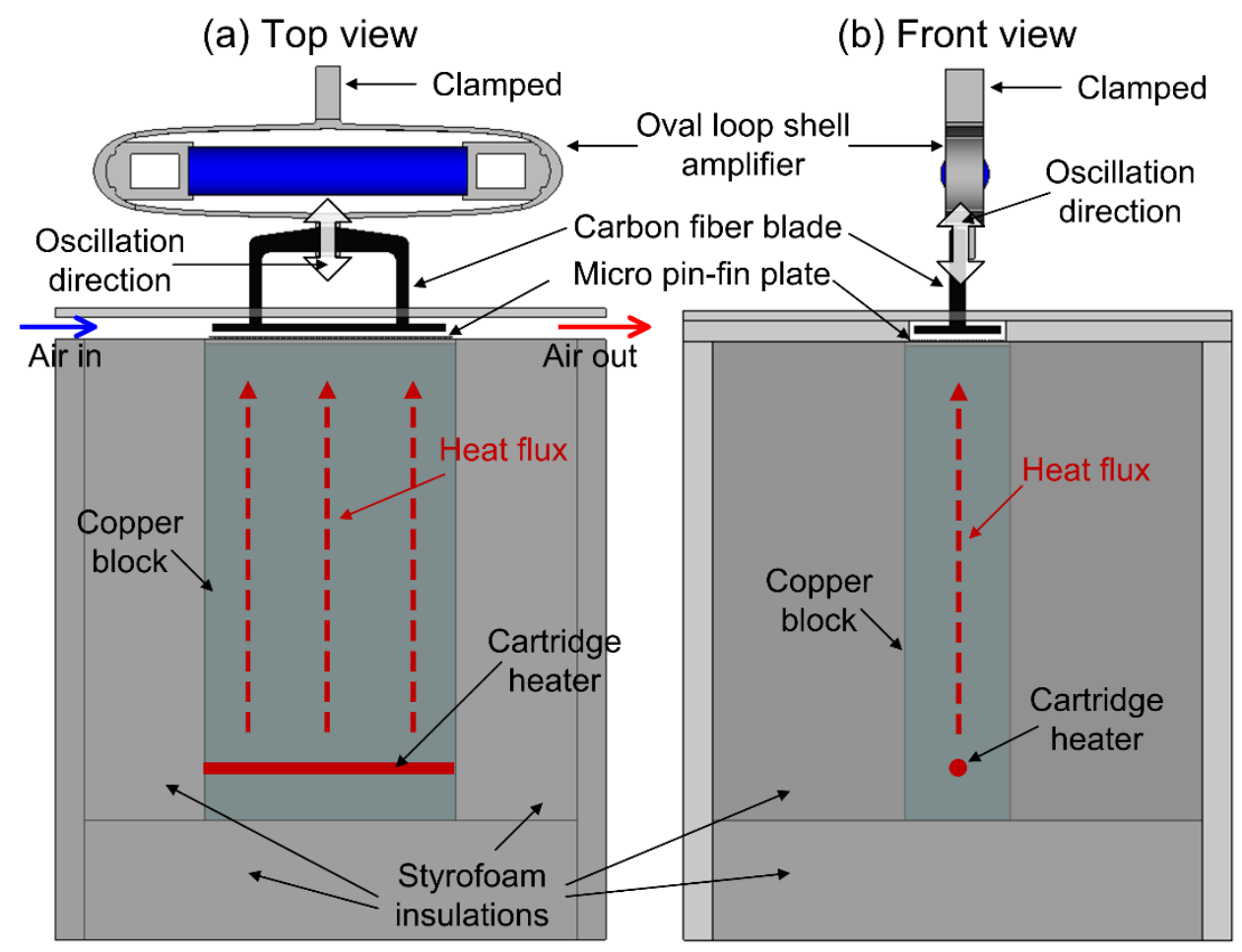

Fig. 4 Test section of the single channel heat transfer experiment with micro pin-fin surface and PTA, (a) top view, (b) front view showing the inlet of the channel

A schematic of heat transfer experiment loop is described in Fig. 5. An external suction pump generates air flow through the channel. A flow meter and a valve to measure and control the channel flow rate are positioned between the test section and the pump. A pressure tap at the outlet adapter of the channel is connected to a manometer to measure pressure drop across the entire channel. A function generator and a voltage amplifier provide an amplified, sinusoidal voltage signal to the agitator drive. 


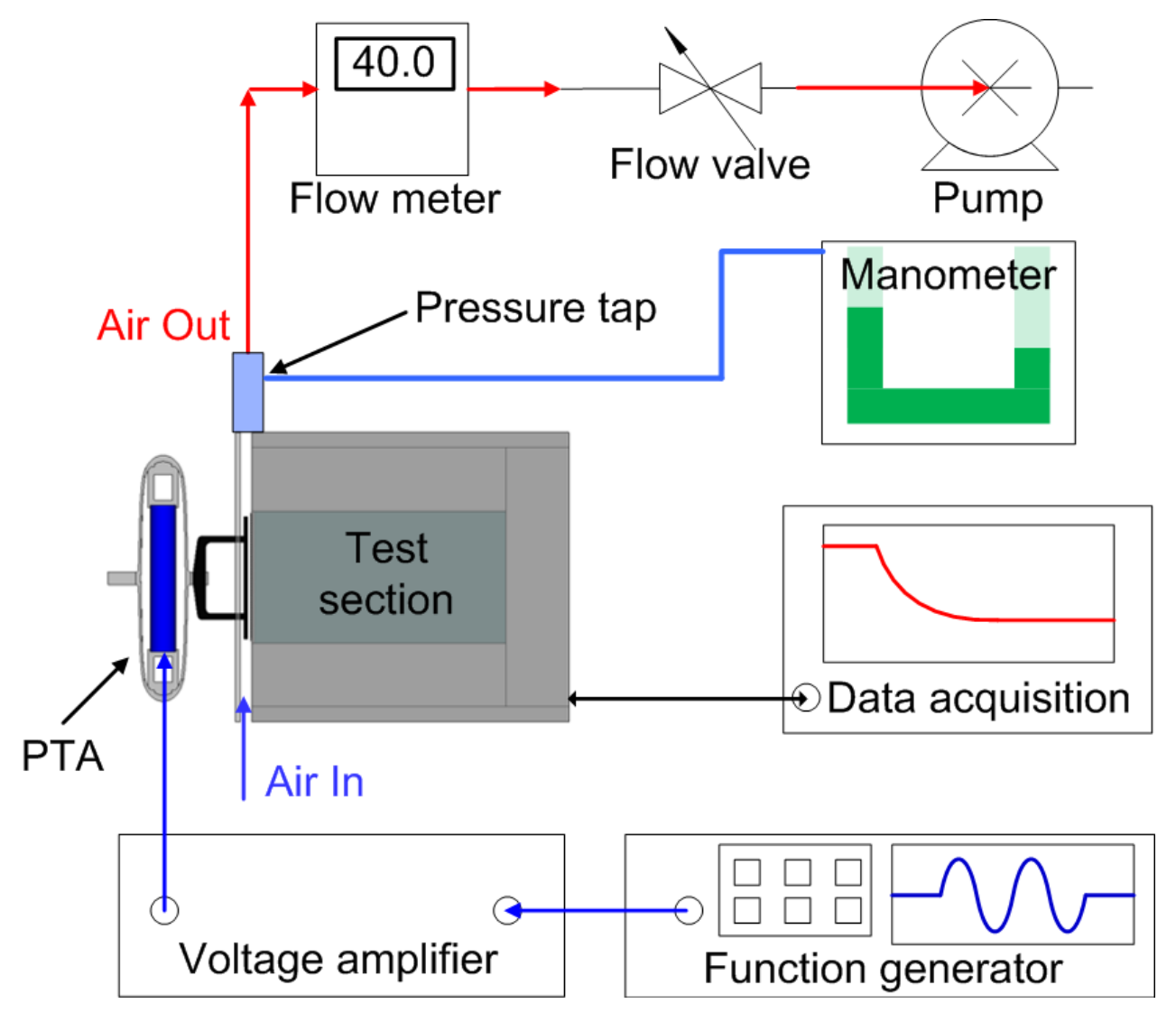

Fig. 5 Schematic of single channel heat transfer experiment facility

\section{Heat transfer and pressure drop experiments}

\subsection{Data reduction}

Eleven micro pin-fin plates were fabricated and sequentially tested in the channel without an agitator to establish baseline data for comparison to the cases with the agitators. Dimensions and structural properties of the eleven micro pin-fin plates are summarized in Table 1. The heights of the pin fins vary from $150 \mu \mathrm{m}$ to $400 \mu \mathrm{m}$. The diameters change from $75 \mu \mathrm{m}$ to 700 $\mu \mathrm{m}$. For all cases, the pitch to diameter ratio, $\mathrm{S} / \mathrm{D}$, is three, except for the case of H150D75, which has $\mathrm{S} / \mathrm{D}=6$. Among the eleven samples, the case of $\mathrm{H} 400 \mathrm{D} 250$ has the largest area increase to $103.6 \%$ of the plain surface area. 
Table 1. Dimensions of micro pin fins

\begin{tabular}{|c|c|c|c|c|c|}
\hline Micro Pin-Fin & $\begin{array}{c}\mathrm{H} \\
(\mu \mathrm{m})\end{array}$ & $\begin{array}{c}\mathrm{D} \\
(\mu \mathrm{m})\end{array}$ & $\begin{array}{c}\mathrm{S} \\
(\mu \mathrm{m})\end{array}$ & $\mathrm{S} / \mathrm{D}$ & Area Increase $(\%)$ \\
\hline H150D75 & 150 & 75 & 450 & 6 & 29.7 \\
H150D150 & 150 & 150 & 450 & 3 & 63.3 \\
H150D200 & 150 & 200 & 600 & 3 & 46.5 \\
H250D250 & 250 & 250 & 750 & 3 & 63.3 \\
H250D400 & 250 & 400 & 1200 & 3 & 38.1 \\
H350D350 & 350 & 350 & 1050 & 3 & 63.3 \\
H350D450 & 350 & 450 & 1350 & 3 & 48.4 \\
H400D250 & 400 & 250 & 750 & 3 & 103.6 \\
H400D400 & 400 & 400 & 1200 & 3 & 63.3 \\
H400D600 & 400 & 600 & 1800 & 3 & 40.9 \\
H400D700 & 400 & 700 & 2100 & 3 & 34.5 \\
\hline
\end{tabular}

Heat transfer coefficients and Nusselt numbers are calculated to investigate the thermal performance of the micro pin-fin surfaces with and without the operation of agitators. The heat transfer coefficient (h) is calculated using a log mean temperature difference (LMTD) method as below:

$$
\mathrm{h}=\mathrm{q} / \mathrm{A} \cdot \Delta \mathrm{T}_{\text {LMTD }}
$$

where $\mathrm{q}$ and $\mathrm{A}$ are heat transfer from the cartridge heater and convection area of the micro pinfin surfaces, respectively. Herein, A is denoting the base projected area of the micro pin-fin plate. The LMTD is calculated as:

$$
\Delta \mathrm{T}_{\mathrm{LMTD}}=\frac{\left[\left(\mathrm{T}_{\text {sur }}-\mathrm{T}_{\text {in }}\right)-\left(\mathrm{T}_{\text {sur }}-\mathrm{T}_{\text {out }}\right)\right]}{\ln \left[\left(\mathrm{T}_{\text {sur }}-\mathrm{T}_{\text {in }}\right) /\left(\mathrm{T}_{\text {sur }}-\mathrm{T}_{\text {out }}\right)\right]}
$$

where $T_{\text {in }}, T_{\text {out }}$ and $T_{\text {sur }}$ are the air temperatures of inlet, outlet and the micro pin-fin plate, respectively. Ten thermocouples are used to measure temperatures $\left(T_{\text {sub,i }}\right) 2.0 \mathrm{~mm}$ below the micro pin-fin surface. The distance of $2.0 \mathrm{~mm}$ includes a contact gap between the copper block and the micro pin-fin plate. Therefore, the surface temperatures $\left(T_{\text {sur, }}\right)$ of the micro pin-fin plate are found by extrapolation: 


$$
\mathrm{T}_{\text {sur }, \mathrm{i}}=\mathrm{T}_{\text {sub }, \mathrm{i}}-\frac{\mathrm{q}}{\mathrm{A}_{\mathrm{c}}}\left(\frac{1_{\text {sub }}}{\mathrm{k}}+\frac{\mathrm{d}_{\text {gap }}}{\mathrm{k}_{\mathrm{tp}}}\right)
$$

where $A_{c}, k, k_{t p}, 1_{\text {sub }}$ and $d_{\text {gap }}$ are the cross sectional area of the copper block, the thermal conductivity of the copper block, the thermal conductivity of the thermal paste, the distance between the convection surface and thermocouples, excluding the contact gap and the thickness of contact gap, respectively. These ten surface temperatures are averaged to obtain the temperature $\left(\mathrm{T}_{\text {sur }}\right)$ of the micro pin-fin surface. The Nusselt number is computed from the heat transfer coefficient as:

$$
\mathrm{Nu}=\mathrm{hd}_{\mathrm{h}} / \mathrm{k}_{\text {air }}
$$

where $\mathrm{d}_{\mathrm{h}}$ and $\mathrm{k}_{\text {air }}$ are the hydraulic diameter of the channel and the thermal conductivity of air, respectively. A flow resistance of the channel is another important factor to document since micro pin fins increase frictional losses and require more pump power to drive air flow through the channel. A static pressure drop across the entire channel length is measured at the outlet adapter that connects the channel to the pump using a water-filled manometer. The static pressure drop $\left(\Delta \mathrm{P}_{\text {static }}\right)$ of the entire channel is calculated as:

$$
\Delta \mathrm{P}_{\text {static }}=2 \mathrm{zg} \cdot\left(\rho_{\text {water }}-\rho_{\text {air }}\right)
$$

where $\mathrm{z}, \mathrm{g}, \rho_{\text {water }}$ and $\rho_{\text {air }}$ are the manometer reading, gravity, water density and air density, respectively. To get the pressure drop of the heated, micro pin-finned section (test section), the pressure losses at the channel inlet and exit and other losses in the channel other than the test section are experimentally evaluated and subtracted from the measured entire channel pressure drop. For the calculation of these losses, a case with a plain surface was used to measure the pressure drop across only the heated section by locating two pressure taps, one right before and one right after the test section. This was taken out from the entire channel measured static 
pressure drop. The net is the summed pressure losses in the channel except for the test section region. This term should be the same for all the testing conditions of this paper. Therefore, for all other micro pin-fin surface and installed agitator combined cases, this term was subtracted from the entire channel pressure drop to calculate the pressure drop across only the test section. The friction factor for the test section can be calculated as:

$$
f=2 d_{\text {test }} \Delta P_{\text {test }} / \rho_{\text {air }} L V_{\text {test }}^{2}
$$

where $\mathrm{d}_{\text {test }}, \Delta \mathrm{P}_{\text {test }}, \mathrm{L}$ and $\mathrm{V}_{\text {test }}$ are the test section hydraulic diameter, pressure drop, length and velocity, respectively. Uncertainty analysis is done to estimate uncertainties of the heat transfer coefficients and pressure drops based on the standard methods for propagation of uncertainty. The uncertainty of $4 \%$ is given to the convection surface area. The uncertainty in temperature measurements is given as $0.5^{\circ} \mathrm{C}$. The cartridge heater uses alternating current (AC). Therefore, time varying voltages to the heater are measured with an oscilloscope to calculate averaged heat generation of the heater. The resistor of $0.2 \Omega$ with an error of $0.1 \%$ is used to measure the current through the heater. The oscilloscope has a measurement accuracy of $3 \%+1 \mathrm{mV}$. The corresponding uncertainty of heat input is $4.4 \%$ based on the above factors. Experience with heaters of this type show that the power factor is essentially unity. The total uncertainty in heat transfer coefficient is $6.1 \%$. For the pressure drop calculations, $2 \%$ of uncertainty is given to the reading of the manometer. Repeating the same process, the uncertainty in pressure drop calculations is $6.2 \%$.

\subsection{Heat transfer results}

To compare the overall performance of the micro pin-fin surfaces without the agitation effects, the performance index described in [26, 29, and 34] is evaluated for the eleven micro pin-fin surfaces using the equation: 


$$
\varepsilon=\frac{\left(\mathrm{Nu} / \mathrm{Nu}_{\mathrm{p}}\right)}{\left(\mathrm{f} / \mathrm{f}_{\mathrm{p}}\right)^{1 / 3}}
$$

where $\mathrm{Nu}_{\mathrm{p}}$ and $\mathrm{f}_{\mathrm{p}}$ are the Nusselt number and friction factor of the plain surface plate, respectively. Note that the $\mathrm{Nu}$ value in the numerator includes the improvement due to added area of the pin fins, since the heat transfer coefficient is based on projected area. Figure 6 shows the comparison of performance index for the eleven micro pin-fin cases tested without the agitator installed in the single channel. If the index is larger than 1, the heat transfer enhancement over the plain surface is greater than the pressure drop increase due to the micro pin-fin surfaces. The greater index represents better performance of the micro pin-fin surfaces, considering both thermal and hydraulic aspects. As a result, the surface H250D400 shows the best performance among the eleven surfaces for all the channel flow rates tested. However, this is not necessarily the best case under agitation. Therefore, the surface of H400D250, showing relatively poor performance, is also selected for testing with agitation.

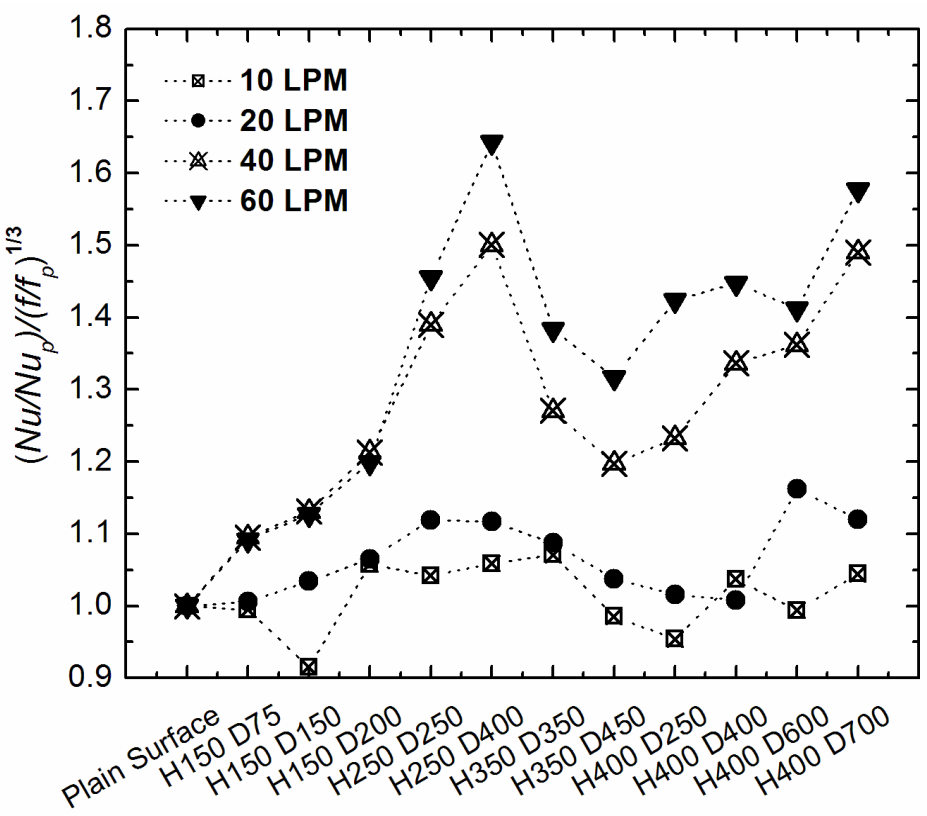

Fig. 6 Performance index comparison of eleven micro pin-fin surfaces tested without agitation 
The heat transfer experiments of the selected micro pin-fin surfaces are performed with the actuators operating at two different frequencies, 596 and $920 \mathrm{~Hz}$. Heat transfer coefficients of the micro pin-fin surfaces under agitation at channel throughflow rates of 10, 20, 40, 60 LPM are shown in Figs. 7, 8, 9 and 10, respectively. Channel flow conditions are listed in Table 2.

Table 2. Channel flow conditions of single channel heat transfer experiments

\begin{tabular}{|c|c|c|c|c|}
\hline Cross flow rate & 10 LPM & 20 LPM & 40 LPM & 60 LPM \\
\hline Velocity at inlet (m/s) & 1.9 & 3.9 & 7.8 & 11.6 \\
\hline Velocity at test section (m/s) & 2.8 & 5.7 & 11.3 & 16.9 \\
\hline Reynolds number (inlet) & 823 & 1646 & 3293 & 4938 \\
\hline
\end{tabular}

The agitator plate operates at peak-to-peak displacements from $0.4 \mathrm{~mm}$ to $1.4 \mathrm{~mm}$ with $0.2 \mathrm{~mm}$ steps adjusted by different applied voltages to the PZT stack. At a channel flow rate of 10 LPM (Fig. 7), a heat transfer coefficient of about $80 \mathrm{~W} / \mathrm{m}^{2} \mathrm{~K}$ is achieved from the plain surface. The micro pin-fin surface of H250D400 increased a heat transfer coefficient by $20 \%$ up to about 100 $\mathrm{W} / \mathrm{m}^{2} \mathrm{~K}$ when the agitators are not in operation. When there is the agitator installed but not in operation, the surface of H400D250 provided obviously better thermal performance over the case of H250D400. Once the agitators are turned on, the effects of translational agitation are clearly seen in all the cases. At a lower operating frequency of $596 \mathrm{~Hz}$, two micro pin-fin surfaces give similar performance values with a displacement of $0.4 \mathrm{~mm}$, with some deviations as the displacement increases. At a frequency of $920 \mathrm{~Hz}$, the surface H250D400 shows higher heat transfer coefficients over the entire displacement range. However, the differences fall within the uncertainty of $6.1 \%$. At a lower flow rate of $10 \mathrm{LPM}$, the two micro pin-fin surfaces show similar heat transfer performance when agitation effects are present. Once the peak-to-peak displacement reaches $1.4 \mathrm{~mm}$, the micro pin-fin surfaces do not have a noticeable benefit over the plain surface performance value at the higher frequency of $920 \mathrm{~Hz}$. Overall, at a flow rate of 10 LPM, the micro pin-fin surface with translational agitation gave a heat transfer coefficient of 
$236 \mathrm{~W} / \mathrm{m}^{2} \mathrm{~K}$, which is $280 \%$ of the value of the non-agitated, but blade installed, plain surface case.

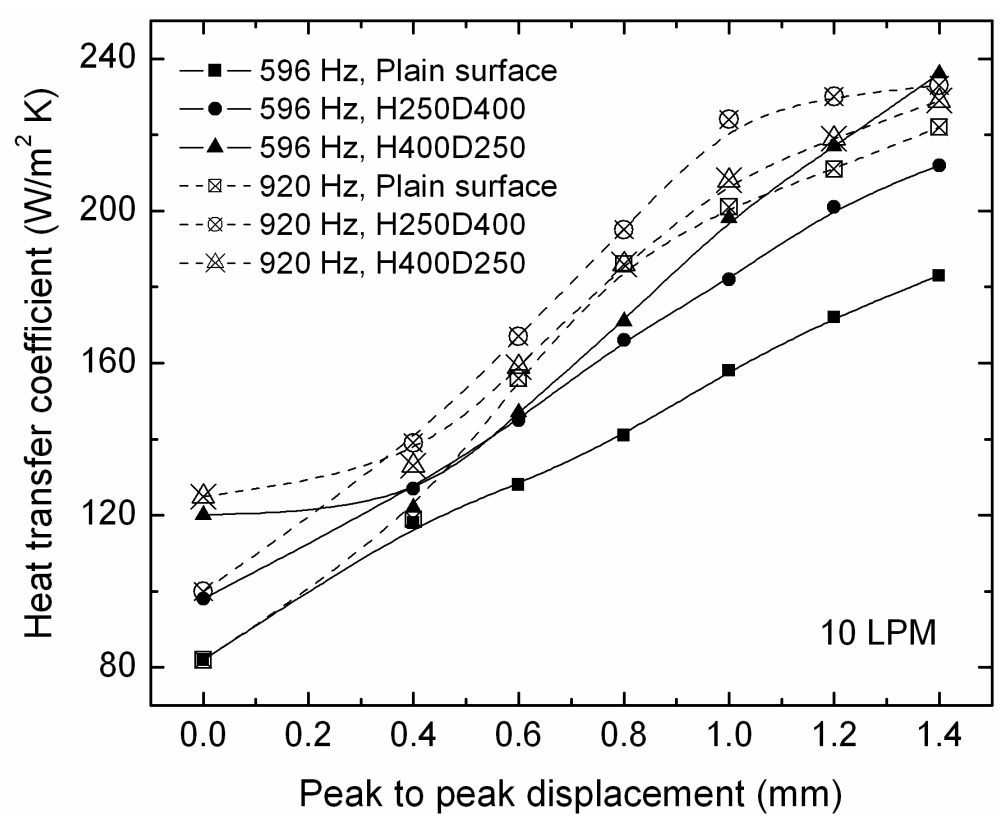

Fig. 7 Heat transfer coefficients of micro pin-fin surfaces under translational agitations at a channel flow rate of 10 LPM

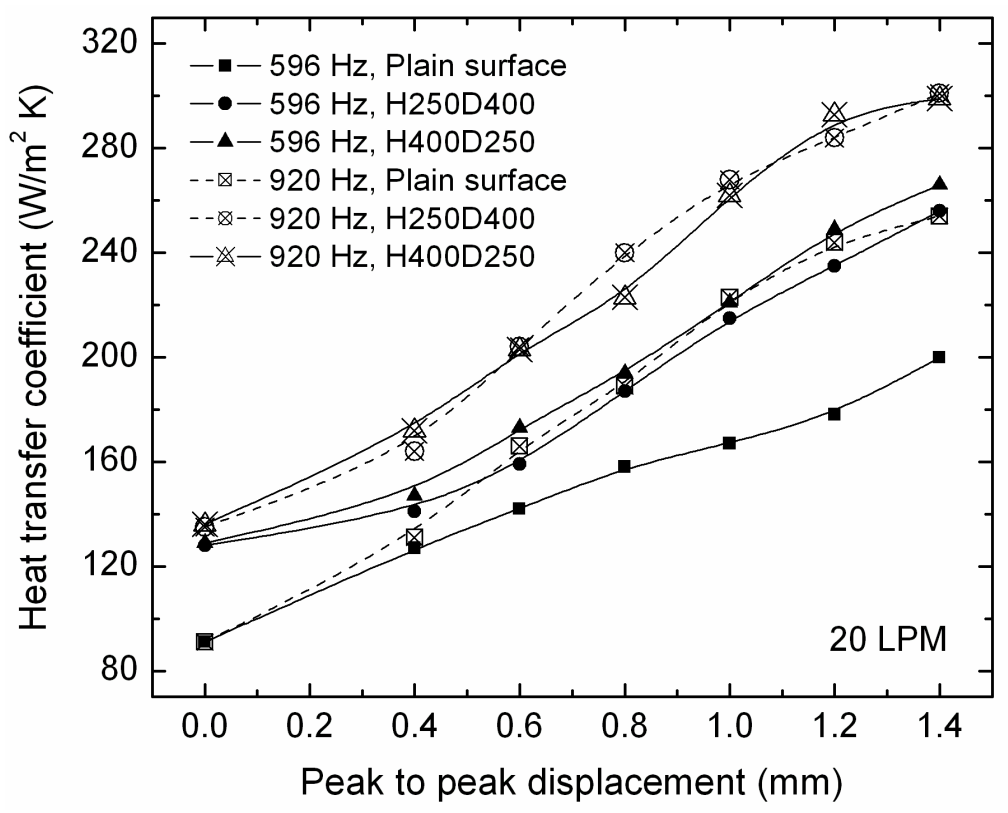

Fig. 8 Heat transfer coefficients of micro pin-fin surfaces under translational agitations at a channel flow rate of 20 LPM 
When the flow rate is increased to 20 LPM, similar patterns are found (Fig. 8). The micro pin-fin surfaces provide obvious improvement in heat transfer compared to the plain surface performance. However, it is difficult to distinguish thermal performance differences between the two micro pin-fin surface cases under agitation. On the other hand, as the flow rate increases to 40 LPM (Fig. 9), surface H400D250 begins to show better thermal performance over the H250D400 surface. At a frequency of $596 \mathrm{~Hz}$, surface H400D250 maintains superiority throughout the entire displacement range. However, at a higher frequency of $920 \mathrm{~Hz}$, as the displacement increases the differences between the two micro pin-fin surfaces become negligible. Overall, higher-frequency agitation gives more heat transfer enhancement with a micro pin-fin surface of H400D250 at $40 \mathrm{LPM}$. At $40 \mathrm{LPM}$, a heat transfer coefficient of $368 \mathrm{~W} / \mathrm{m}^{2} \mathrm{~K}$ is achieved from the micro pin-fin surface of H400D250 cooled by $920 \mathrm{~Hz}$ agitation at a peak-topeak displacement of $1.4 \mathrm{~mm}$. This is $250 \%$ of the non-agitated, plain surface value.

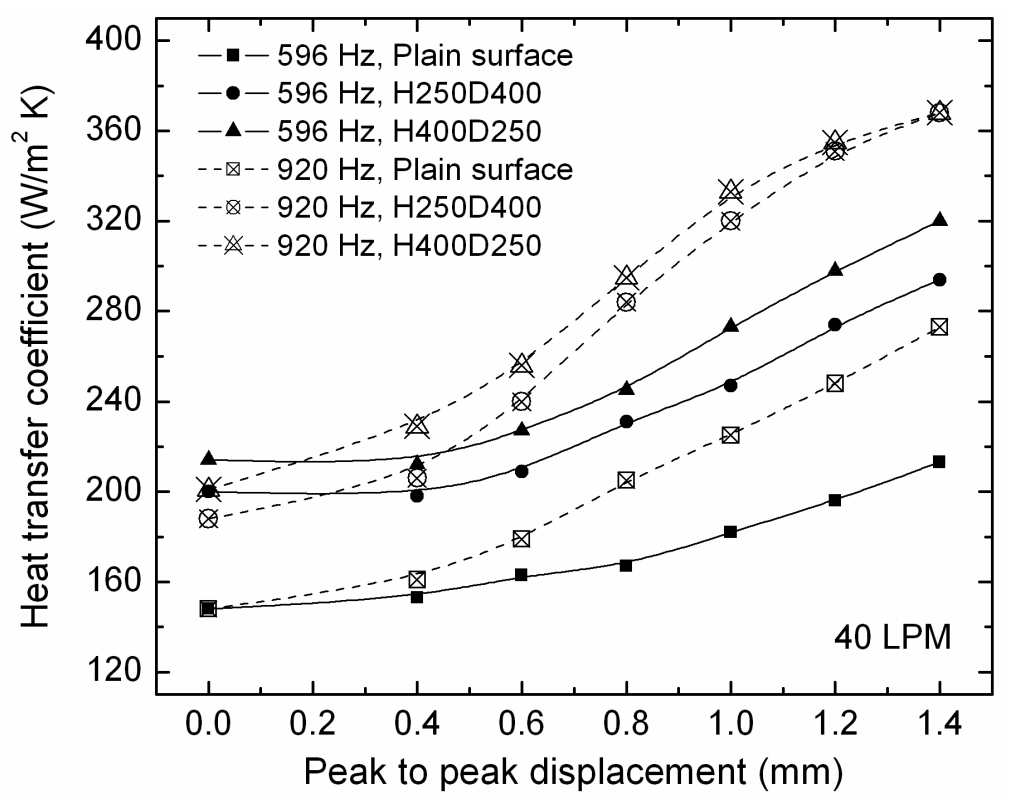

Fig. 9 Heat transfer coefficients of micro pin-fin surfaces under translational agitations at a channel flow rate of 40 LPM 
At the highest flow rate of 60 LPM, the effects of micro pin-fin surfaces and translational agitation become more obvious, as shown in Fig. 10. Heat transfer enhancement due to micro pin-fin surfaces is larger than for the lower flow rate cases. Among the two micro pin-fin surfaces, H400D250 clearly shows better performance under all the operating conditions. At 60 $\mathrm{PM}$, translational agitation at $920 \mathrm{~Hz}$ increases heat transfer coefficients of the H400D250 surface up to $422 \mathrm{~W} / \mathrm{m}^{2} \mathrm{~K}$. This is $230 \%$ of the value for the non-agitated, plain-surface case. From the heat transfer test results taken at different operating conditions, it is noted that the micro pin-fin surfaces and agitators perform better at higher channel flow rates (turbulent regime).

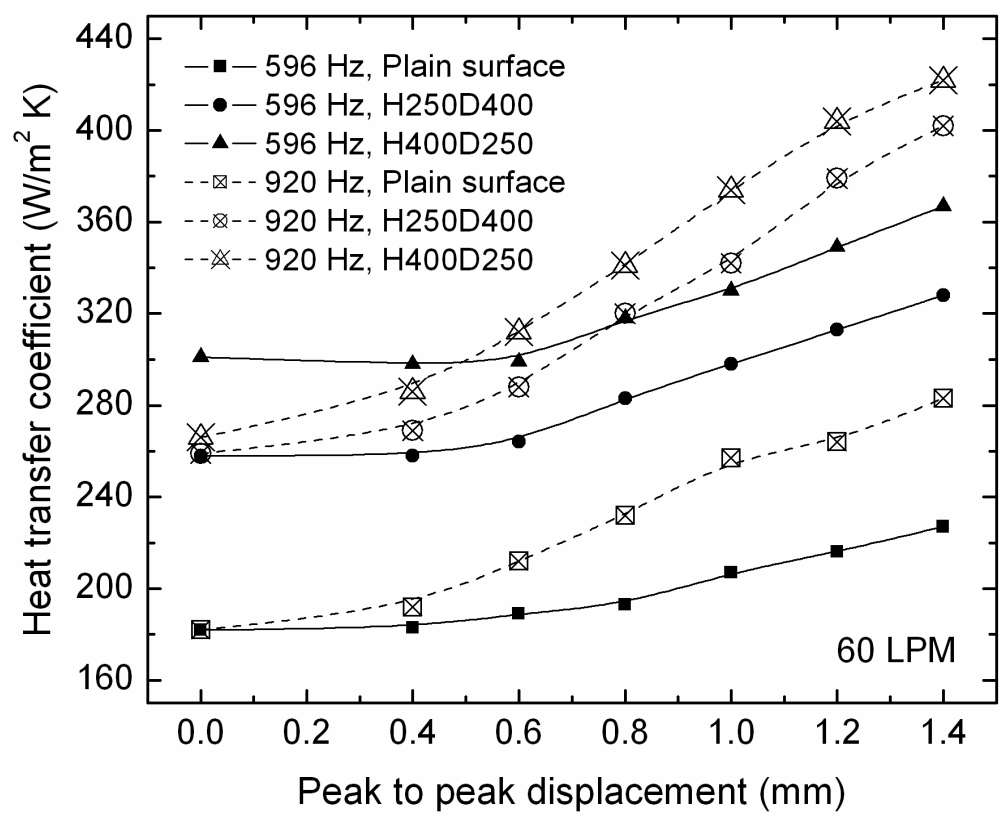

Fig. 10 Heat transfer coefficients of micro pin-fin surfaces under translational agitations at a channel flow rate of 60 LPM

\subsection{Pressure drop}

Pressure drops over the micro pin-fin surfaces under translational agitation at different channel flow rates are presented in Fig. 11. At lower flow rates of 10 and 20 LPM, pressure drop increases due to micro pin-fin surfaces are not significant. Overall, adding more agitation has 
less impact on the pressure drop increase than does flow rate increase. At the lower flow rates of 10 and 20 LPM, two micro pin fin surfaces show very similar pressure drop values under the same flow rate and agitation displacement. On the other hand, when a flow rate increases to 40 LPM, the differences in pressure drop between the two micro pin-fin surfaces become more apparent. At 40 LPM, the H250D400 surface has a larger pressure drop than does the H400D250 surface at $596 \mathrm{~Hz}$. However, at a higher frequency of $920 \mathrm{~Hz}$, the H400D250 surface has the larger pressure drop. When a flow rate increases to 60 LPM, the pressure drop over the $\mathrm{H} 400 \mathrm{D} 250$ surface is above $150 \mathrm{~Pa}$ and rises to $280 \mathrm{~Pa}$ with the actuator operating at $920 \mathrm{~Hz}$, with a $1.4 \mathrm{~mm}$ peak-to-peak displacement.
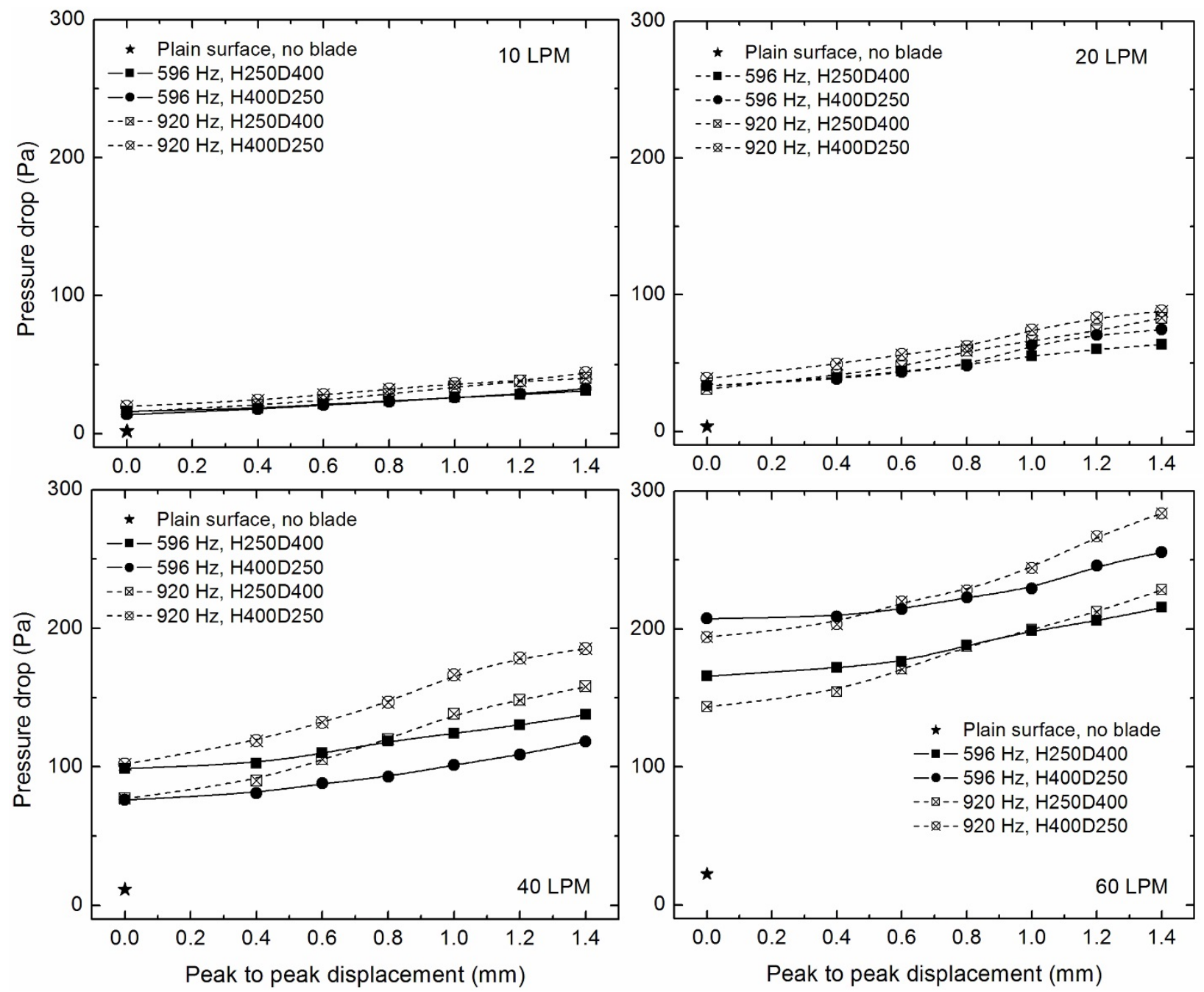
Fig. 11 Pressure drops over micro pin-fin surfaces under translational agitations

At the flow rate of 60 LPM, the H400D250 surface shows larger pressure drops at both operating frequencies over the entire displacement range. It is interesting to see that the higher frequency operation does not necessarily lead to larger pressure drop compared to lower frequency agitation. At 40 LPM and $596 \mathrm{~Hz}$ agitation over the H250D400 surface, a larger pressure drop is observed, compared to the $920 \mathrm{~Hz}$ agitation case on the same surface when the agitation displacement is smaller than $0.6 \mathrm{~mm}$. However, the higher frequency agitation case gives larger pressure drops when the agitation displacement is larger than $0.8 \mathrm{~mm}$. At $60 \mathrm{LPM}$, a similar situation is observed. At displacements smaller than $0.6 \mathrm{~mm}$, lower frequency agitation of 596 $\mathrm{Hz}$ shows larger pressure drops for both micro pin-fin surface cases. Once the displacement becomes larger than $0.8 \mathrm{~mm}$, the pressure drop of the higher agitation frequency case becomes larger than that of the lower frequency case. Overall, it is not easy to find specific patterns of pressure drop with respect to different operating frequencies and micro pin-fin surfaces.

\section{Nusselt number and Stanton number}

In order to characterize the combined effects of channel flow rates and translational agitation of the system, a total Reynolds number $\left(\mathrm{Re}_{\text {tot }}\right)$ was proposed by Yeom et al. [35] as:

$$
\operatorname{Re}_{\text {tot }}=\sqrt{\operatorname{Re}_{\mathrm{c}}+\mathrm{Re}_{\mathrm{a}}}
$$

where $\mathrm{Re}_{\mathrm{c}}$ and $\mathrm{Re}_{\mathrm{a}}$ are the Reynolds numbers for a channel flow and translational agitation, defined as:

$$
\begin{aligned}
\operatorname{Re}_{\mathrm{c}} & =\frac{\mathrm{V}_{\mathrm{in}} \mathrm{d}_{\mathrm{h}}}{v} \\
\operatorname{Re}_{\mathrm{a}} & =\frac{\omega \mathrm{Ad} \mathrm{d}_{\mathrm{b}}}{v}
\end{aligned}
$$


where $V_{i n}, \omega, A, d_{h}, d_{b}$ and $v$ are the channel inlet velocity, frequency of the agitator, maximum mean-to-peak displacement, hydraulic diameters of the channel with blade, hydraulic diameter of the blade, and kinematic viscosity, respectively. The hydraulic diameter of the blade is:

$$
d_{b}=4 A_{b} / P_{b}
$$

where $A_{b}$ and $P_{b}$ are the area and perimeter of the blade plate, respectively. Similarly, the hydraulic diameter of the channel is defined as:

$$
\mathrm{d}_{\mathrm{h}}=4 \mathrm{~A}_{\mathrm{h}} / \mathrm{P}_{\mathrm{h}}
$$

where $A_{h}$ and $P_{h}$ are the channel cross sectional area and wetted perimeter calculated when the blade cross section is subtracted from the channel. By substituting Equations (12) and (13) into Equation (11), the total Reynolds number becomes:

$$
\mathrm{Re}_{\mathrm{tot}}=\frac{\sqrt{\left(\mathrm{V}_{\mathrm{in}} \mathrm{d}_{\mathrm{h}}\right)^{2}+\left(\omega \mathrm{Ad}_{\mathrm{b}}\right)^{2}}}{v}
$$

Therefore, the total Reynolds number contains all aspects of air currents generated in the test section by the channel flow and agitation. This leads the heat transfer coefficient (in Figs. $7 \sim 10$ ) to be re-plotted with respect to the total Reynolds number. 


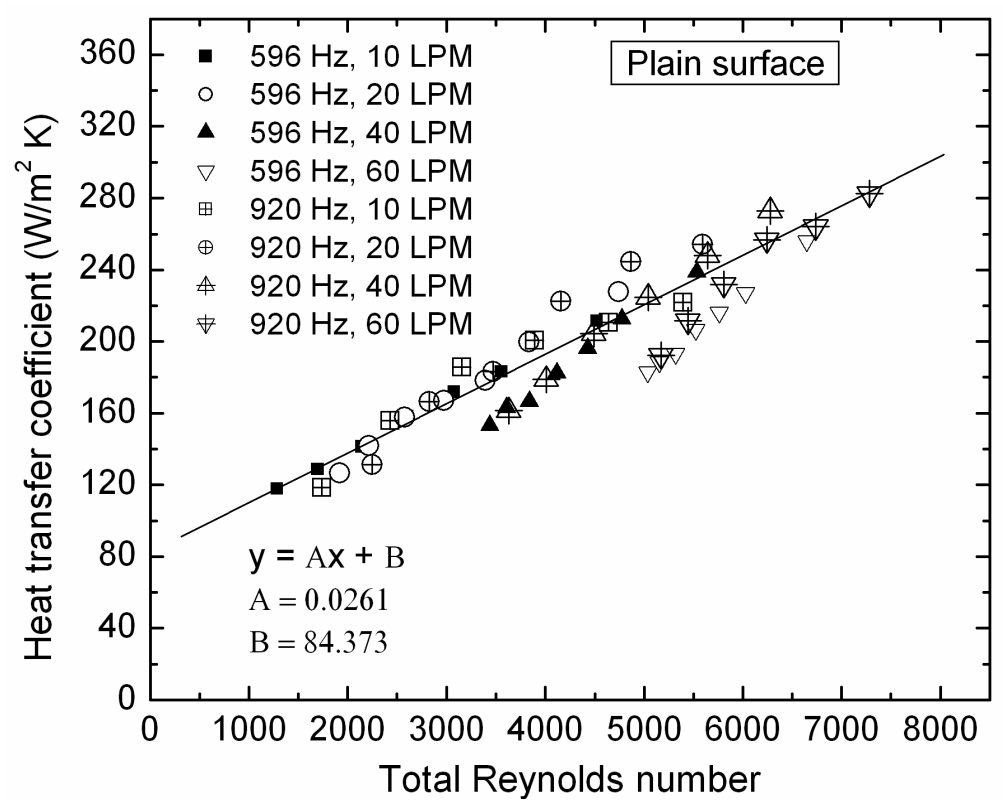

Fig. 12 Heat transfer coefficient of plain surface with respect to total Reynolds number

Figure 12 shows heat transfer coefficients of the plain surface with the corresponding total Reynolds number for each operating condition. The heat transfer coefficients are linearly distributed along with total Reynolds number. The R-squared error of the linear fit is $85.9 \%$ for the plain surface. The heat transfer coefficients of two micro pin-fin surfaces also show linear relationships with the total Reynolds number as shown in Figs. 13 and 14. 


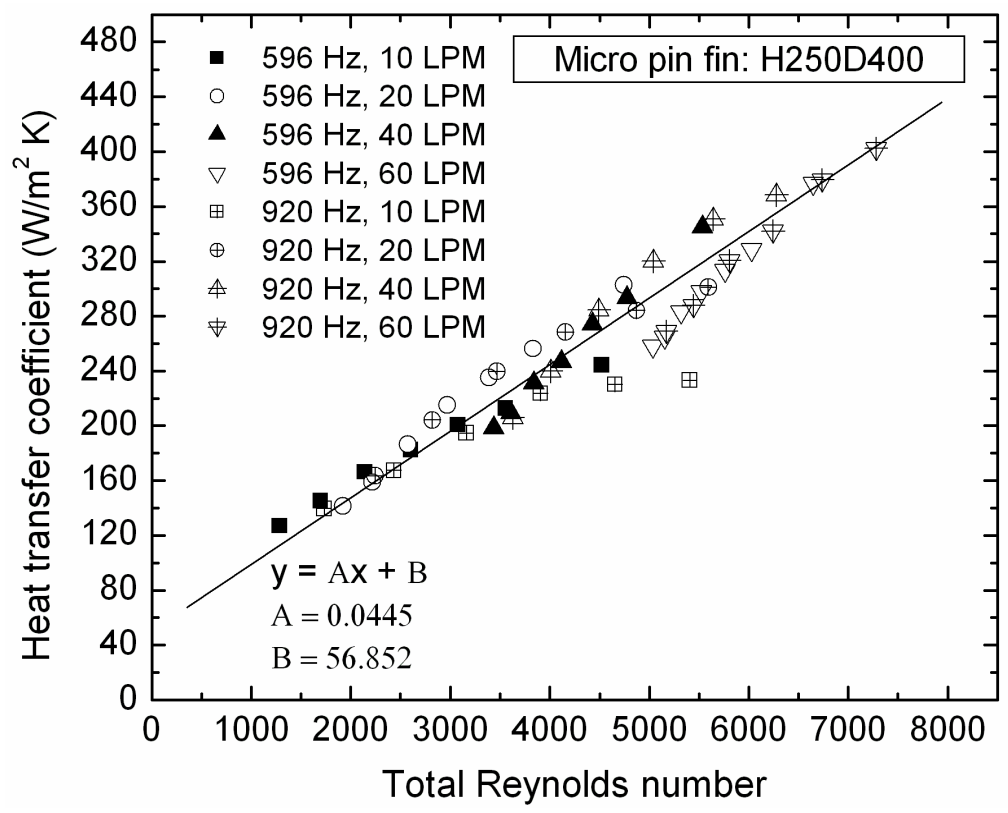

Fig. 13 Heat transfer coefficient of the surface H250D400 with respect to total Reynolds number

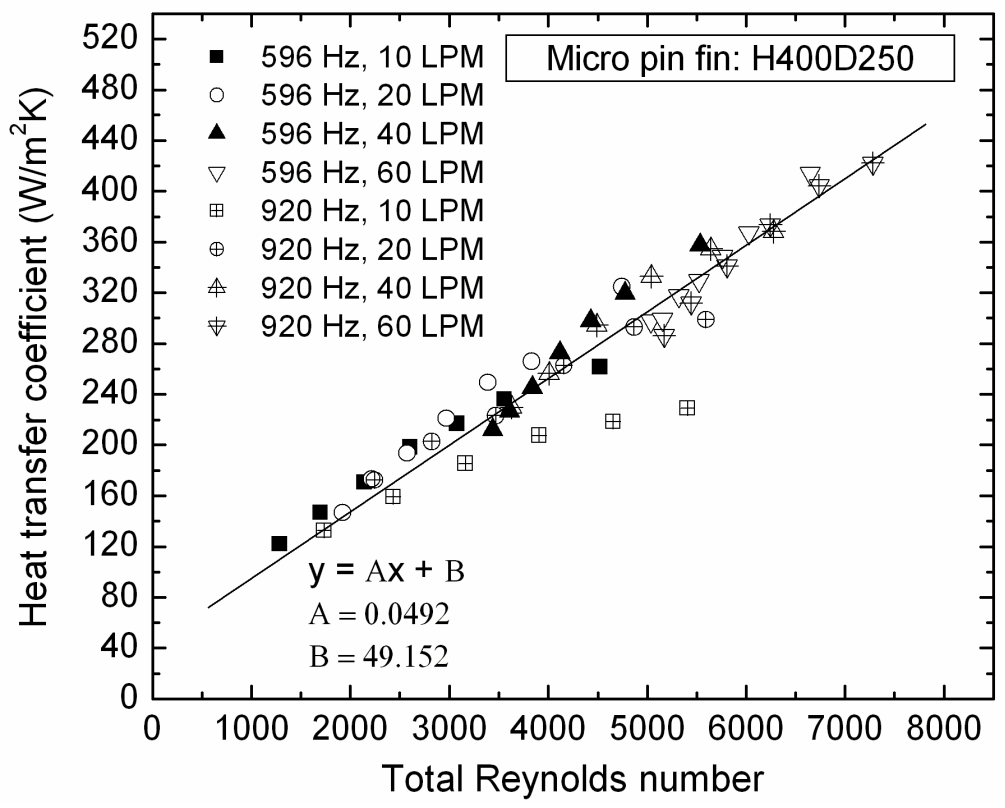

Fig. 14 Heat transfer coefficient of the surface H400D250 with respect to total Reynolds number

The micro pin-fin surfaces increase slopes of the linear fits compared to those for the plain surface. The constants, A and B, of the linear relations for the three surfaces are summarized in Table 3. 
Table 3. Constants of linear relation between the heat transfer coefficient and total Reynold numbers

\begin{tabular}{|c|c|c|c|c|}
\hline & A & B & R-squared error (\%) & Stanton number \\
\hline Plain surface & 0.0261 & 84.4 & 85.9 & 0.00999 \\
\hline H250D400 & 0.0445 & 56.8 & 81.3 & 0.01730 \\
\hline H400D250 & 0.0492 & 49.2 & 80.9 & 0.01913 \\
\hline
\end{tabular}

From the linear relationship between the heat transfer coefficient, h, and the total Reynolds number, the expression for Nusselt number $(\mathrm{Nu})$ is derived as:

$$
\mathrm{Nu}=\frac{(\mathrm{h}-\mathrm{B}) \mathrm{d}_{\mathrm{h}}}{\mathrm{k}_{\text {air }}}=\mathrm{CRe}_{\text {tot }} \operatorname{Pr}
$$

where $\mathrm{k}_{\mathrm{air}}$ and $\mathrm{Pr}$ is the thermal conductivity and Prandtl number of air. The constant $\mathrm{C}$ is:

$$
\mathrm{C}=\frac{\mathrm{A}}{\operatorname{Pr}} \cdot \frac{\mathrm{d}_{\mathrm{h}}}{\mathrm{k}_{\mathrm{f}}}
$$

The Nusselt numbers of the surfaces calculated based on Equation (17) are presented with respect to the total Reynolds number in Fig. 15.

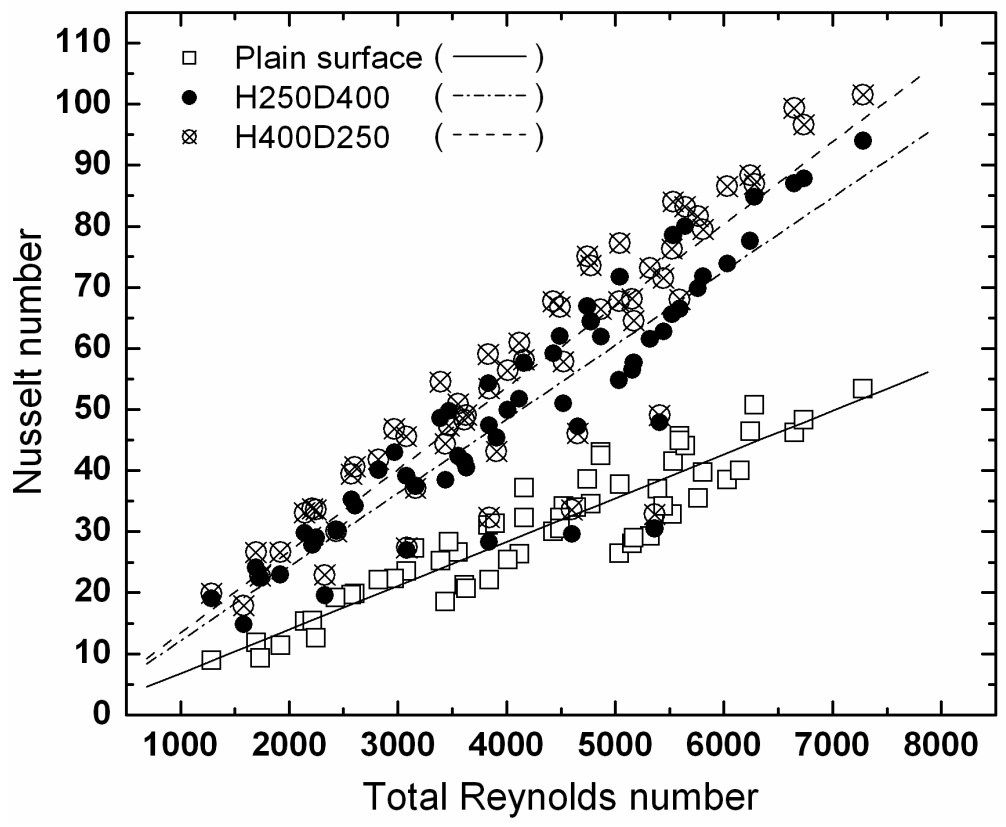

Fig. 15 Nusselt number with respect to total Reynolds number 
The results show that the micro pin-fin surface of H400D250 provides better cooling capability over the H250D400 surface under translational agitation with channel flow. By substituting Equations (16) into Equation (17), the Stanton number, the non-dimensionalized heat transfer coefficient, can be obtained with further arrangement:

$$
\mathrm{St}=\frac{(\mathrm{h}-\mathrm{B})}{\rho_{\text {air }} \mathrm{cV} \text { eff }}=\mathrm{C}
$$

where the effective velocity of the system is given by:

$$
\mathrm{V}_{\text {eff }}=\sqrt{\left(\mathrm{V}_{\mathrm{in}}\right)^{2}+(\omega \mathrm{A})^{2}\left(\frac{\mathrm{d}_{\mathrm{b}}}{\mathrm{d}_{\mathrm{h}}}\right)^{2}}
$$

Therefore, one can estimate the cooling capability of the agitator in the channel flow at specific operating conditions in terms of the operating frequency, displacement, blade size and channel flow rate using the definitions of Stanton number and effective velocity. According to Equation (19), the constant $C$ is identical to the Stanton number of the surface. Figure 16 compares the Stanton numbers calculated both from Equation (18) and Equation (19) for two micro pin-fin surfaces and the plain surface. It shows that the cooling performance of each surface could be characterized by the Stanton number. In addition, heat transfer enhancement of the micro pin-fin surfaces with translational agitation over the plain surface can be clearly confirmed. The calculation errors of the Stanton numbers from Equation (19) are shown in Fig. 16. Comparing the Stanton numbers of three surfaces, the micro pin-fin surface H400D250 improved thermal performance to $191 \%$ of the plain surface value while surface, H250D400, improved thermal performance to $173 \%$ of the plane surface value. 


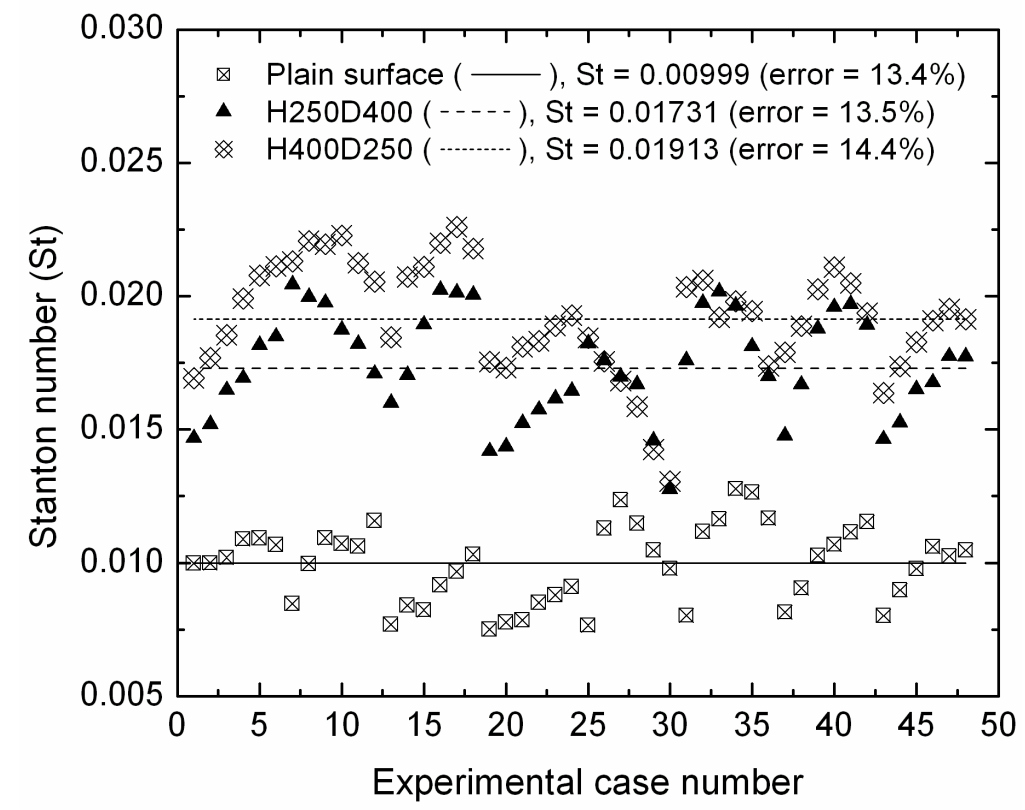

Fig. 16 Stanton number of the micro pin-fin surfaces and plain surfaces

\section{Thermal performance estimation of a full size active heat sink}

The single channel test section used for the heat transfer experiments of the current study represents one portion of an active heat sink equipped with multiple channels with a blade agitator in each and with a micro pin-finned surfaces. Therefore, estimating the overall thermal resistance of the full size active heat sink based on the results of the single channel experiments would be desirable and helpful for better understanding of the proposed cooling technology. Figure 17(a) shows the virtual heat sink that consists of 26 channels and a flow diverter in the center, designed for a $89 \mathrm{~mm}$ by $114 \mathrm{~mm}$ ( 3.5 by $4.5 \mathrm{inch})$ footprint. 


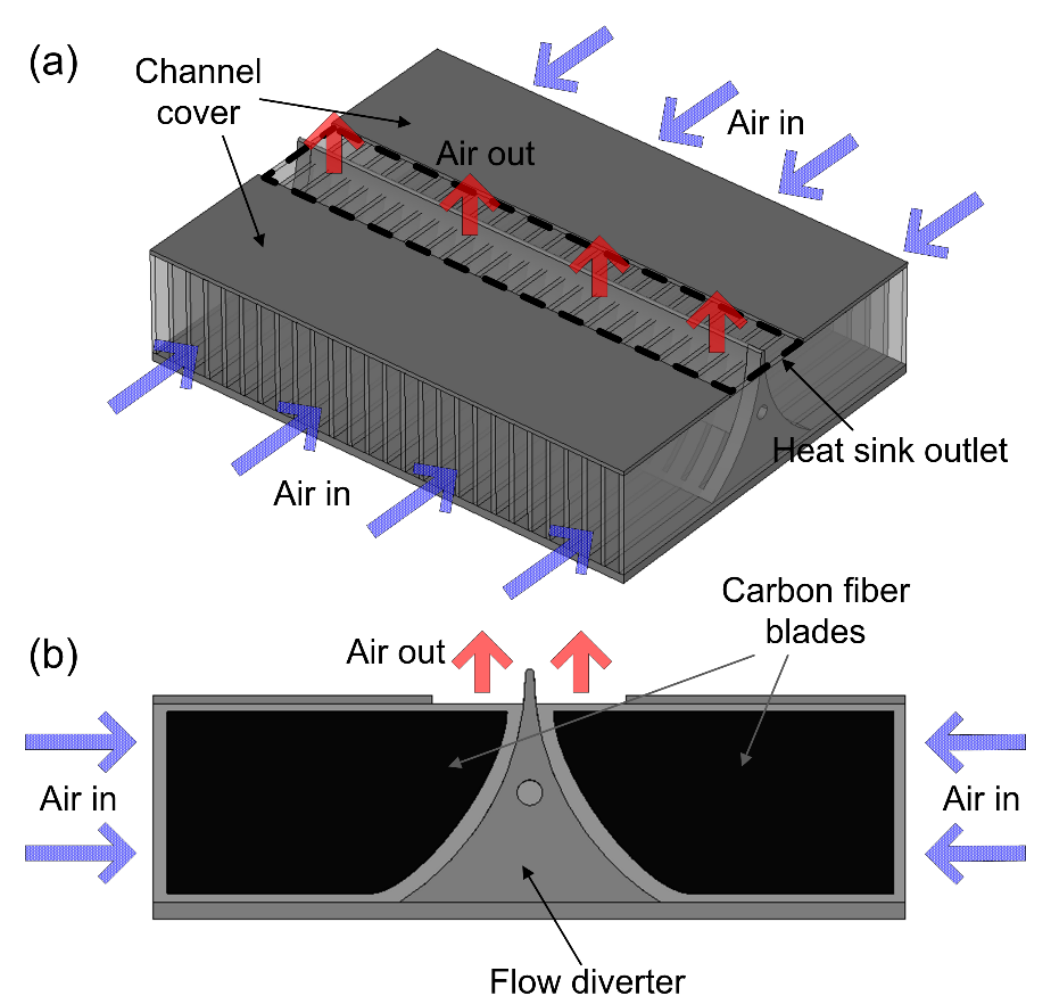

Fig. 17 Schematic of virtual active heat sink module (a) heat sink and flow path, (b) single heat sink channel with agitator blades installed

The heat sink channels are assumed to have the H400D250 surface as it shows better thermal performance than that of the H250D400 surface. Air flow comes from the both sides of the heat sink (blue arrows in Fig. 17), turns 90 degrees by the diverter and leaves upward (red arrows in Fig. 17) in the center of the heat sink. The sides of the heat sink, except for the channel inlets and outlet, are covered by adiabatic plates. Figure 17(b) shows a cross sectional view of the heat sink channel. The carbon fiber agitator blades positioned in the channel fit the channels with a clearance of $1 \mathrm{~mm}$. The channel has a height and width of 23.5 and $3.4 \mathrm{~mm}$, respectively, at the inlet plain. The heat sink fin thickness is $1.1 \mathrm{~mm}$. The agitator blade thickness is $0.6 \mathrm{~mm}$. It is assumed that the heat transfer coefficients measured from the single channel test at the previous section are the average heat transfer coefficients of the entire active heat sink surfaces at the equivalent operating conditions. The overall heat dissipation $\left(\mathrm{q}_{\text {sink }}\right)$ and inlet air temperature 
( $\mathrm{T}_{\text {sink,in }}$ ) of the active heat sink are assumed to be $1.0 \mathrm{~kW}$ and $30{ }^{\circ} \mathrm{C}$, respectively. The air outlet temperature $\left(\mathrm{T}_{\text {sink,out }}\right)$ of the heat sink can be calculated as:

$$
\mathrm{T}_{\text {sink,out }}=\mathrm{T}_{\text {sin }, \text { in }}+\frac{\mathrm{q}_{\text {sink }}}{\rho_{\text {air }} \mathrm{Q}_{\text {sink }}}
$$

where $\mathrm{Q}_{\text {sink }}$ is the converted heat sink flow rate that provides the same channel velocity as the single channel heat transfer experiments. The converted heat sink flow rates are summarized in Table 4.

Table 4. Flow rate conversion between single channel test and full size active heat sink

\begin{tabular}{|c|c|c|c|c|}
\hline Single channel test flow rate (LPM) & 10 & 20 & 40 & 60 \\
\hline Converted system flow rate (LPM) & 589 & 1181 & 2362 & 3543 \\
\hline
\end{tabular}

Herein, it is assumed that the heat sink surfaces are isothermal. The heat sink base temperature ( $\left.\mathrm{T}_{\text {sink }}\right)$ must be calculated to get the thermal resistance of the active heat sink module with the assumed operating conditions of the heat sink. With the heat transfer coefficients (h) measured from the single channel heat transfer experiments, the following equation using the LMTD is valid:

$$
\mathrm{q}_{\text {sin } \mathrm{k}}=\mathrm{h} \cdot \mathrm{A}_{\text {sin } \mathrm{k}} \frac{\left(\mathrm{T}_{\text {sink }}-\mathrm{T}_{\text {sink.out }}\right)-\left(\mathrm{T}_{\text {sink }}-\mathrm{T}_{\text {sink.in }}\right)}{\ln \left(\frac{\mathrm{T}_{\text {sink }}-\mathrm{T}_{\text {sink.uut }}}{\mathrm{T}_{\text {sink }}-\mathrm{T}_{\text {sink.in }}}\right)}
$$

where $\mathrm{A}_{\text {sink }}$ is the convection surface of the active heat sink without considering the area increase due to the micro pin-fin surfaces. From Equation (22), the heat sink base temperature is calculated as:

$$
\mathrm{T}_{\text {sink }}=\frac{\mathrm{T}_{\text {sink.out }}-\mathrm{T}_{\text {sink,in }} \exp (\mathrm{Z})}{1-\exp (\mathrm{Z})}
$$

where $\mathrm{Z}$ is expressed as: 


$$
\mathrm{Z}=\frac{\mathrm{h} \cdot \mathrm{A}_{\text {sin } \mathrm{k}}\left(\mathrm{T}_{\text {sin } \mathrm{kin}}-\mathrm{T}_{\text {sin k.out }}\right)}{\mathrm{q}_{\text {sin } \mathrm{k}}}
$$

Therefore, the thermal resistance $\left(\mathrm{R}_{\mathrm{th}}\right)$ of the active heat sink can be computed as:

$$
\mathrm{R}_{\mathrm{th}}=\frac{\mathrm{T}_{\text {sin } \mathrm{k}}-\mathrm{T}_{\text {sin } \mathrm{kin}}}{\mathrm{q}_{\sin \mathrm{k}}}
$$

Figure 18 shows the thermal resistance of the virtual active heat sink calculated from Equation (25) with respect to the total Reynolds number of the heat sink channel.

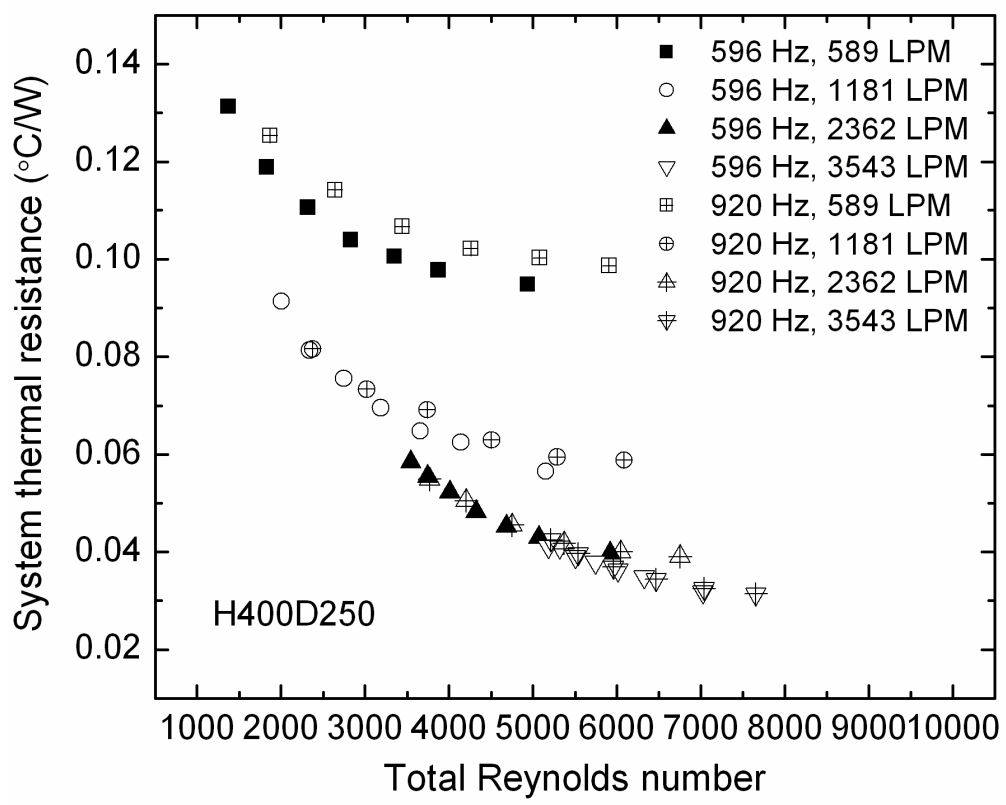

Fig. 18 Thermal resistance estimation of the virtual active heat sink based on single channel test results

It is apparent that higher operating frequency, large displacement, and flow rates lead a lower thermal resistance. The effect of a displacement on the thermal resistance is significant, but tends to decrease as the total Reynolds number increases at a given operating frequency and flow rate. However, a frequency has little impact on the thermal resistance as agitation with two different frequencies generates similar ranges of thermal resistance at a given flow rate. The thermal resistance significantly improves as the flow rate increases. The active heat sink can achieve a 
thermal resistance of less than $0.04{ }^{\circ} \mathrm{C} / \mathrm{W}$ at a high flow rate of 3,543 LPM, which gives the heat sink inlet velocity of $14.2 \mathrm{~m} / \mathrm{s}$.

\section{Conclusions}

In this paper, the new cooling technique that combines both active and passive components of heat transfer enhancement was proposed to achieve efficient removal of heat from high power electronics. The active component is the piezoelectric translational agitator that can generate high-frequency, translational oscillation of a thin, rigid blade. This high-frequency translational agitation is utilized to cool the micro pin-fin surface. The pin fins represent the passive heat transfer augmentation component of the system. An intensive heat transfer study was performed to verify the performance of the proposed technique by using a single channel test facility. Eleven micro pin-fin plate samples were fabricated and their performance index values, which characterize both thermal and hydrodynamic performance, were compared. As a result, the micro pin-fin surfaces H250D400 and H400D250 were selected for further heat transfer experiments in which a piezoelectric translational agitator is incorporated. For instance, a case with the agitator operating at $920 \mathrm{~Hz}$ with a peak-to-peak displacement of $1.4 \mathrm{~mm}$ with the H400D250 pin finned surface enhanced the heat transfer coefficient to $250 \%$ and $230 \%$ of plain-wall, non-agitated values at channel flow rates of 40 and 60 LPM, respectively. The pressure drops across the test section of the single channel facility were measured and compared. It was confirmed that the agitation effects on pressure drop are not substantial, regardless of operating frequency. However, channel flow rate has a significant impact on increasing pressure drop. In order to consider the combined effects of cross flow and translational agitation on cooling performance of the system, an analyses using the total Reynolds number and Stanton 
number were conducted. It was confirmed that each surface has its own value of Stanton number that characterizes thermal performance. Based on the Stanton number analysis, the micro pin-fin surface H400D250 with translational agitation improved the overall cooling capability about $191 \%$, compared to the plain surface with the same agitation and channel flow conditions. A fullscale, active heat sink module aided with agitation and micro pin-fin surface enhancement was proposed. Its thermal performance was estimated using the heat transfer coefficients measured in the single channel experiment. The proposed active heat sink module with an array of 26 channels installed with 52 agitator blades is shown to provide a thermal resistance of about $0.04{ }^{\circ} \mathrm{C} / \mathrm{W}$ at its best operating condition. This represents a very good system thermal resistance. The power required to drive the multiple-blade agitator and channel flow are important factors not addressed in this paper.

\section{Acknowledgements}

This work was supported in part by the Defense Advanced Research Projects Agency (DARPA) MACE Program. The views expressed are those of the authors, and do not reflect the official policy or position of the Department of Defense or the U.S. Government. Approved for Public Release, Distribution Unlimited.

\section{Nomenclatures}

$\begin{array}{ll}A & \text { Convection surface area } \\ A_{b} & \text { Carbon fiber blade area } \\ A_{c} & \text { Cross sectional area of copper block } \\ A_{\text {sink }} & \text { Convection surface area of the virtual active heat sink } \\ d_{b} & \text { Hydraulic diameter of the blade } \\ d_{h} & \text { Hydraulic diameter of the channel } \\ f & \text { Friction coefficient } \\ f_{p} & \text { Friction coefficient of plain surface } \\ f_{\text {up,down }} & \text { Friction coefficient of upstream and downstream extensions of single channel }\end{array}$




$\begin{array}{ll}\mathrm{g} & \text { Standard gravity } \\ \mathrm{h} & \text { Heat transfer coefficient } \\ \mathrm{K}_{\text {loss,inlet }} & \text { Inlet loss coefficient } \\ \mathrm{k} & \text { Thermal conductivity of copper } \\ \mathrm{k}_{\text {air }} & \text { Thermal conductivity of air } \\ \mathrm{k}_{\text {tp }} & \text { Thermal conductivity of thermal paste } \\ \mathrm{Nu} & \text { Nusselt number } \\ \mathrm{Nu}_{\mathrm{p}} & \text { Nusselt number of plain surface } \\ \Delta \mathrm{P}_{\text {static }} & \text { Static pressure drop } \\ \Delta \mathrm{P}_{\text {total }} & \text { Total pressure drop } \\ \Delta \mathrm{P}_{\text {test }} & \text { Pressure drop across the test section of the single channel } \\ \mathrm{Pr} & \text { Prandtl number } \\ \mathrm{p}_{\mathrm{b}} & \text { Perimeter of the agitator blade } \\ \mathrm{Q}_{\text {sink }} & \text { Volumetric flow rate of the virtual active heat sink } \\ \mathrm{q} & \text { Heat input of the single channel heat transfer } \\ \mathrm{q}_{\text {sink }} & \text { Heat input of the virtual active heat sink } \\ \mathrm{Re}_{\mathrm{c}} & \text { The channel Reynolds number } \\ \mathrm{Re}_{\mathrm{a}} & \text { The Reynolds number of PTA } \\ \mathrm{Re}_{\text {tot }} & \text { The total Reynolds number } \\ \mathrm{R}_{\text {th }} & \text { Thermal resistance } \\ \mathrm{St}_{\mathrm{T}} & \text { Stanton number } \\ \mathrm{T}_{\text {in }} & \text { Single channel inlet temperature } \\ \mathrm{T}_{\text {out }} & \text { Single channel outlet temperature } \\ \mathrm{T}_{\text {sink }} & \text { Active heat sink base temperature } \\ \mathrm{T}_{\text {sink,in }} & \text { Air inlet temperature of the active heat sink } \\ \mathrm{T}_{\text {sink,out }} & \text { Air outlet temperature of the active heat sink } \\ \mathrm{T}_{\text {sub }} & \text { Temperature measured below the convection surface } \\ \mathrm{T}_{\text {sur }} & \text { Averaged surface temperature } \\ \Delta \mathrm{T}_{\mathrm{LMTD}} & \text { Log Mean Temperature difference } \\ \mathrm{V}_{\text {con }} & \text { Contraction velocity at the outlet adaptor } \\ \mathrm{V}_{\text {in }} & \text { Channel inlet velocity } \\ v & \text { Kinematic viscosity } \\ \mathrm{z} & \text { Manometer reading } \\ \text { Greek symbols } & \\ \varepsilon & \text { Performance index } \\ \omega & \text { Angular frequency } \\ \rho_{\text {air }} & \text { Density of air } \\ \rho_{\text {water }} & \text { Density of water } \\ & \\ & \end{array}$

\section{[References]}

[1] M. Fabbri, S. Jiang, V.K. Dhir, A Comparative Study of Cooling of High Power Density Electronics Using Sprays and Microjets, Journal of Heat Transfer, 127(1) (2005) 38-48. 
[2] U. Ghoshal, D. Grimm, S. Ibrani, C. Johnston, A. Miner, High-performance liquid metal cooling loops, in: Semiconductor Thermal Measurement and Management Symposium, Twenty First Annual IEEE, 2005, pp. 16-19.

[3] S.C. Mohapatra, D. Loikits, Advances in liquid coolant technologies for electronics cooling, in: Semiconductor Thermal Measurement and Management Symposium, Twenty First Annual IEEE, 2005, pp. 354-360.

[4] X.F. Peng, B.X. Wang, Forced convection and flow boiling heat transfer for liquid flowing through microchannels, International Journal of Heat and Mass Transfer, 36(14) (1993) 34213427.

[5] M. Visaria, I. Mudawar, Application of Two-Phase Spray Cooling for Thermal Management of Electronic Devices, Components and Packaging Technologies, IEEE Transactions on, 32(4) (2009) 784-793.

[6] H.Y. Zhang, D. Pinjala, T.N. Wong, K.C. Toh, Y.K. Joshi, Single-phase liquid cooled microchannel heat sink for electronic packages, Applied Thermal Engineering, 25(10) (2005) 1472-1487.

[7] M. Toda, S. Osaka, Vibration Fan Using the Piezoelectric Polymer $\mathrm{PVF}_{2}$, in: Proceedings of the IEEE, 1979, pp. 1171-1173.

[8] J.H. Yoo, J.I. Hong, W. Cao, Piezoelectric ceramic bimorph coupled to thin metal plate as cooling fan for electronic devices, Sensors and Actuators A: Physical, 79(1) (2000) 8-12.

[9] T. Açikalin, S.M. Wait, S.V. Garimella, A. Raman, Experimental Investigation of the Thermal Performance of Piezoelectric Fans, Heat Transfer Engineering, 25(1) (2004) 4-14.

[10] S.M. Wait, S. Basak, S.V. Garimella, A. Raman, Piezoelectric Fans Using Higher Flexural Modes for Electronics Cooling Applications, Components and Packaging Technologies, IEEE Transactions on, 30(1) (2007) 119-128.

[11] T. Açikalin, S.V. Garimella, Analysis and Prediction of the Thermal Performance of Piezoelectrically Actuated Fans, Heat Transfer Engineering, 30(6) (2009) 487-498.

[12] M. Kimber, S.V. Garimella, A. Raman, Local Heat Transfer Coefficients Induced by Piezoelectrically Actuated Vibrating Cantilevers, Journal of Heat Transfer, 129(9) (2007) 11681176.

[13] S.-F. Liu, R.-T. Huang, W.-J. Sheu, C.-C. Wang, Heat transfer by a piezoelectric fan on a flat surface subject to the influence of horizontal/vertical arrangement, International Journal of Heat and Mass Transfer, 52(11-12) (2009) 2565-2570.

[14] N. Beratlis, M.K. Smith, Optimization of synthetic jet cooling for microelectronics applications [VCSEL array example], in: Semiconductor Thermal Measurement and Management Symposium, Ninteenth Annual IEEE, 2003, pp. 66-73.

[15] R. Mahalingam, N. Rumigny, A. Glezer, Thermal management using synthetic jet ejectors, Components and Packaging Technologies, IEEE Transactions on, 27(3) (2004) 439-444.

[16] Y. Wang, G. Yuan, Y.K. Yoon, M.G. Allen, S.A. Bidstrup, Active cooling substrates for thermal management of microelectronics, Components and Packaging Technologies, IEEE Transactions on, 28(3) (2005) 477-483.

[17] A. Pavlova, M. Amitay, Electronic Cooling Using Synthetic Jet Impingement, Journal of Heat Transfer, 128(9) (2006) 897-907.

[18] M. Arik, Local Heat Transfer Coefficients of a High-Frequency Synthetic Jet during Impingement Cooling over Flat Surfaces, Heat Transfer Engineering, 29(9) (2008) 763-773. 
[19] D.E. Metzger, C.S. Fan, S.W. Haley, Effects of Pin Shape and Array Orientation on Heat Transfer and Pressure Loss in Pin Fin Arrays, Journal of Engineering for Gas Turbines and Power, 106(1) (1984) 252-257.

[20] D.E. Metzger, R.A. Berry, J.P. Bronson, Developing Heat Transfer in Rectangular Ducts With Staggered Arrays of Short Pin Fins, Journal of Heat Transfer, 104(4) (1982) 700-706.

[21] E.M. Sparrow, J.W. Ramsey, C.A.C. Altemani, Experiments on In-line Pin Fin Arrays and Performance Comparisons with Staggered Arrays, Journal of Heat Transfer, 102(1) (1980) 44-50. [22] E.K. Ruth, Experiments on a Crossflow Heat Exchanger With Tubes of Lenticular Shape, Journal of Heat Transfer, 105 (1983) 571-575.

[23] Q. Li, Z. Chen, U. Flechtner, H.-J. Warnecke, Heat transfer and pressure drop characteristics in rectangular channels with elliptic pin fins, International Journal of Heat and Fluid Flow, 19(3) (1998) 245-250.

[24] M.K. Chyu, Y.C. Hsing, V. Natarajan, Convective Heat Transfer of Cubic Fin Arrays in a Narrow Channel, Journal of Turbomachinery, 120(2) (1998) 362-367.

[25] M.K. Chyu, Heat Transfer and Pressure Drop for Short Pin-Fin Arrays With Pin-Endwall Fillet, Journal of Heat Transfer, 112(4) (1990) 926-932.

[26] C. Marques, K.W. Kelly, Fabrication and Performance of a Pin Fin Micro Heat Exchanger, Journal of Heat Transfer, 126(3) (2004) 434-444.

[27] A. Koşar, C. Mishra, Y. Peles, Laminar Flow Across a Bank of Low Aspect Ratio Micro Pin Fins, Journal of Fluids Engineering, 127(3) (2005) 419-430.

[28] Y. Peles, A. Koşar, C. Mishra, C.-J. Kuo, B. Schneider, Forced convective heat transfer across a pin fin micro heat sink, International Journal of Heat and Mass Transfer, 48(17) (2005) 3615-3627.

[29] R.S. Prasher, J. Dirner, J.-Y. Chang, A. Myers, D. Chau, D. He, S. Prstic, Nusselt Number and Friction Factor of Staggered Arrays of Low Aspect Ratio Micropin-Fins Under Cross Flow for Water as Fluid, Journal of Heat Transfer, 129(2) (2007) 141-153.

[30] T. Yeom, T.W. Simon, M. Zhang, M.T. North, T. Cui, High frequency, large displacement, and low power consumption piezoelectric translational actuator based on an oval loop shell, Sensors and Actuators A: Physical, 176 (2012) 99-109.

[31] T. Yeom, T.W. Simon, Y. Yu, M.T. North, T. Cui, Convective Heat Transfer Enhancement on a Channel Wall with a High Frequency, Oscillating Agitator, in: ASME International Mechanical Engineering Congress and Exposition, Denver, Colorado, USA, 2011, pp. 875-884.

[32] T. Yeom, T.W. Simon, Y. Yu, M. Zhang, S. Agrawal, L. Huang, T. Zhang, M.T. North, T. Cui, An active heat sink system with piezoelectric translational agitators and micro pin fin arrays, in: ASME 2012 International Mechanical Engineering Congress and Exposition, Houston, Texas, USA, 2012, pp. 1497-1488.

[33] Y. Yu, T.W. Simon, M. Zhang, T. Yeom, M.T. North, T. Cui, Enhancing heat transfer in air-cooled heat sinks using piezoelectrically-driven agitators and synthetic jets, International Journal of Heat and Mass Transfer, 68(0) (2014) 184-193.

[34] S.C. Siw, M.K. Chyu, T.I.P. Shih, M.A. Alvin, Effects of Pin Detached Space on Heat Transfer and From Pin Fin Arrays, in: ASME Turbo Expo, Glasgow, UK, 2010, pp. 491-500.

[35] T. Yeom, T.W. Simon, L. Huang, M.T. North, T. Cui, Piezoelectric Translation Agitation for Enhancing Forced-Convection Channel-Flow Heat Transfer, International Journal of Heat and Mass Transfer, 55(25) (2012) 7398-7409. 


\section{Figure Captions}

Fig. 1(a) Piezoelectric translational agitator (PTA), (b) PTA at the idle state, (c) operation mode of the PTA.

Fig. 2 Illustration of translational agitator operating with micro pin-fin plate in a narrow channel

Fig. 3 Fabrication process of copper micro pin-fin plate, (a) Ti metal layer deposition, (b) KMPR photoresist deposition, (c) photoresist patterning and Ti layer etching, (d) electroplating of copper micro pin fins, (e) removal of KMPR photoresist and Ti layer residuals, (f) SEM image of micro pin-fin array, $(\mathrm{g})$ micro pin-fin plate

Fig. 4 Test section of the single channel heat transfer experiment with micro pin-fin surface and PTA, (a) top view, (b) front view showing the inlet of the channel

Fig. 5 Schematic of single channel heat transfer experiment facility

Fig. 6 Performance index comparison of eleven micro pin-fin surfaces tested without agitation

Fig. 7 Heat transfer coefficients of micro pin-fin surfaces under translational agitations at a channel flow rate of 10 LPM

Fig. 8 Heat transfer coefficients of micro pin-fin surfaces under translational agitations at a channel flow rate of 20 LPM

Fig. 9 Heat transfer coefficients of micro pin-fin surfaces under translational agitations at a channel flow rate of 40 LPM

Fig. 10 Heat transfer coefficients of micro pin-fin surfaces under translational agitations at a channel flow rate of 60 LPM

Fig. 11 Pressure drops over micro pin-fin surfaces under translational agitations

Fig. 12 Heat transfer coefficient of plain surface with respect to total Reynolds number

Fig. 13 Heat transfer coefficient of the surface H250D400 with respect to total Reynolds number

Fig. 14 Heat transfer coefficient of the surface H400D250 with respect to total Reynolds number

Fig. 15 Nusselt number with respect to total Reynolds number

Fig. 16 Stanton number of the micro pin-fin surfaces and plain surfaces

Fig. 17 Schematic of virtual active heat sink module (a) heat sink and flow path, (b) single heat sink channel with agitator blades installed 
Fig. 18 Thermal resistance estimation of the virtual active heat sink based on single channel test results 